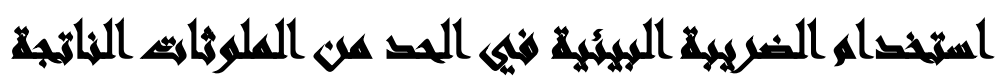

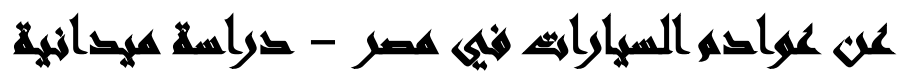

\section{[1 \{]}

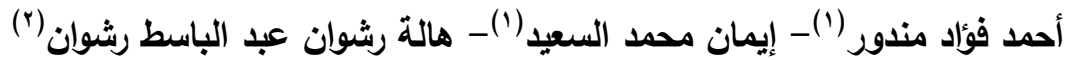

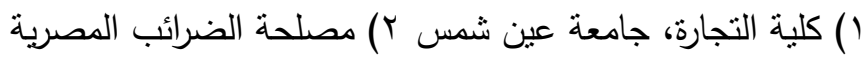

\section{المسترلحص}

تعاني البيئة العالمية بشكل عام ومصر بشكل خاص من مشاكل جمة متعلقة بالبيئة

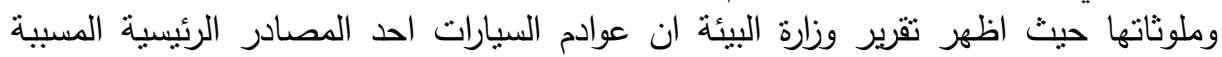

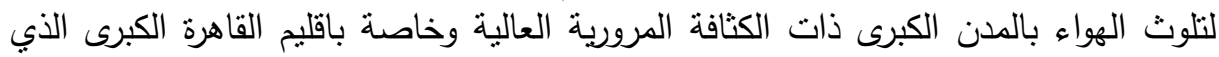

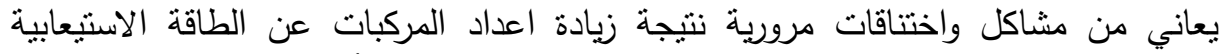

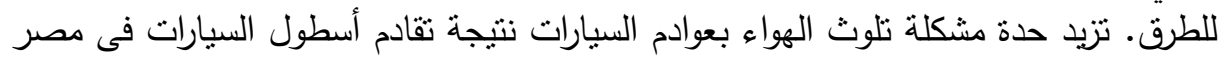

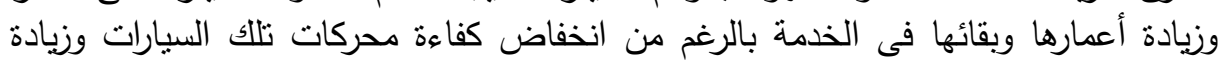

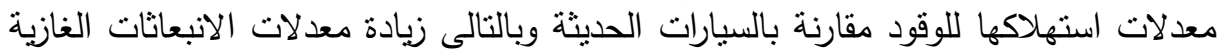

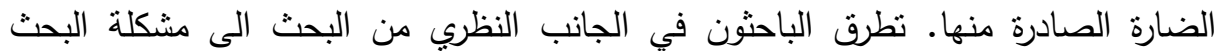

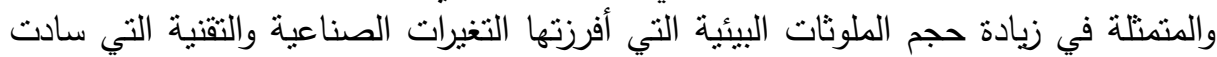

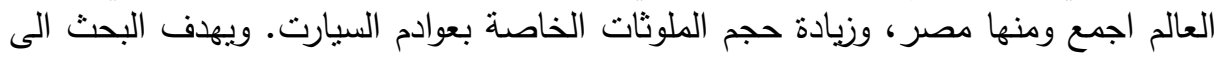

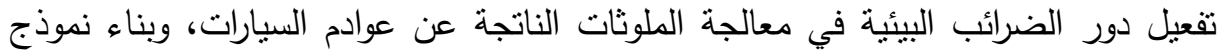

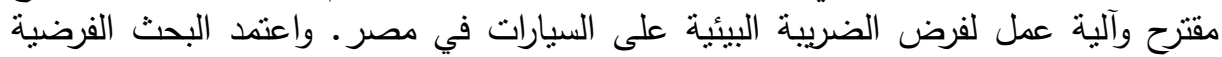

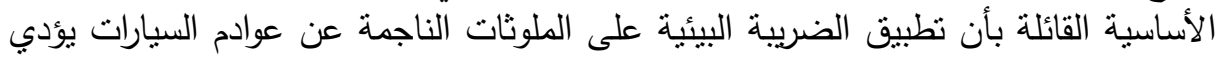

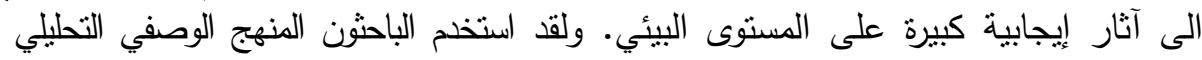

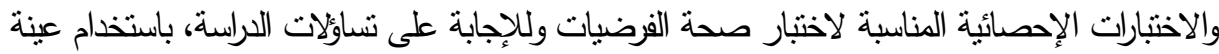

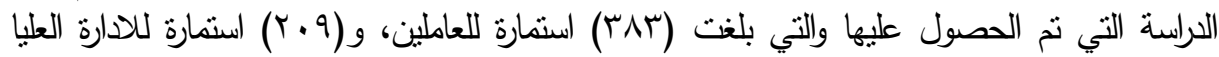

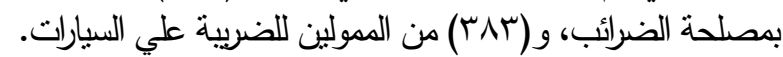
وقد اوضحت النتائج وجود ثأثثر ايجابي للضريبية البيئية على الحد من الملونات النات الناجمة عن عواتم

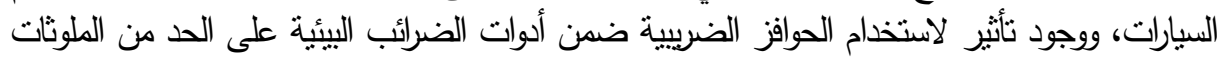

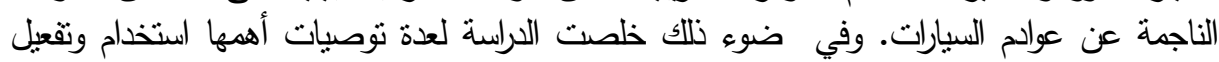

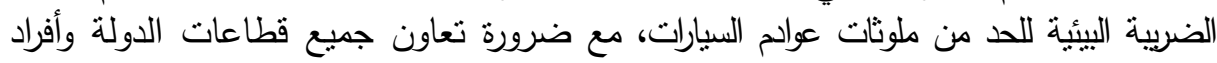

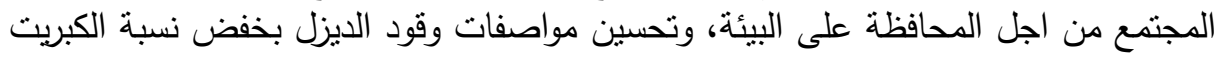
واستخدام التكنولوجيا النظيفة بيئيا في المعامل ووسائل النقل.

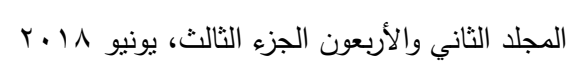


مجلة العلوم البيئية

معهد الدراسات والبحوث البيئية - جامعة عين شمس ليه

\section{المهابـد}

أصبح التلوث البيئي مشكلة من أهم مشاكل القرن الحادي والعشرين نتيجة استغلال البيئة المحيطة واستنزاف مواردها بشكل أضر كثيرا بها، خاصة في ظل التقدم العلمي والتقني الذي التي

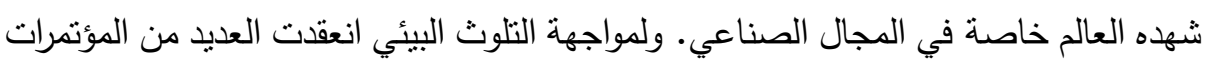

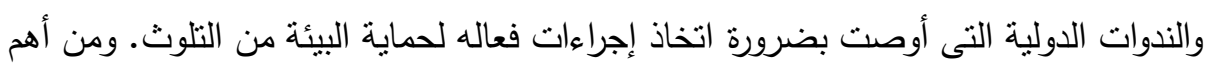
الإجراءات التى أسفرت عنها الأخذ بنظام الضريبة البيئية كوسيلة من وسائل مواجهة التلوث البيئي والحد منه بأسلوب اقتصادي.

ونظراً لما تعانى منه مصر من الآثار الخطيرة للنلوث البيئي، لذا فإن الأمر يستلزم منا سرعة الأخذ بسياسة بيئية للححافظة على البيئة وتحسين نوعيتها وذلك بهدف تجنب التبات الأضرار الحالية والعمل على إزالتها وجعلها عند ادني مستوى ممكن من خلال اتخاذ مجموعة من الأدوات

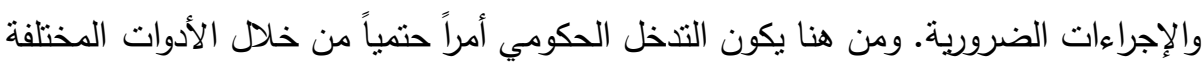
للسياسة البيئة بهدف حماية المجتمع من التلوث (الادارة العامة للبحوث المقارنة، مصلحة المئة

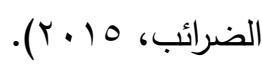

ومن المعروف ايضا ان للضرائب اغراض عدة منها غرض اجتماعي من خلال فرض

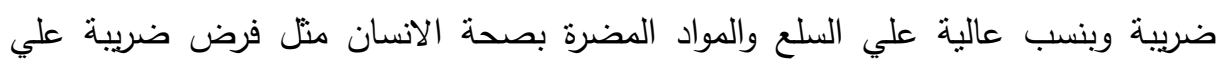

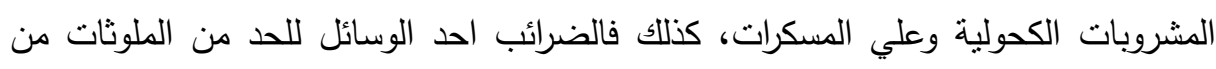
أجل الحفاظ علي صحة الانسان وعلي الموارد الطبيعية فضلاً عن زيادة الايرادات الضريبية

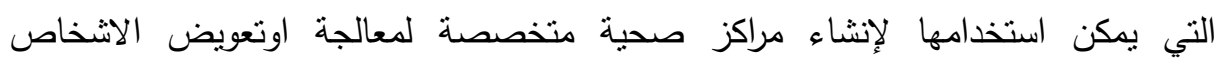
المتأثرين من الاضرار الناجمة عن هذه الملوثات أو توظيفها في مشاريع من شأنها تحسين الأنياء

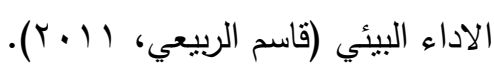

\section{مئم}

تتبع مشكلة البحث من مشكلة عامة ألا وهي زيادة حجم الملوثات البيئية التي أفرزتها التغيرات الصناعية والتقنية التي سادت العالم أجمع، والتي أضرت بالتوازن البيئي الخاص

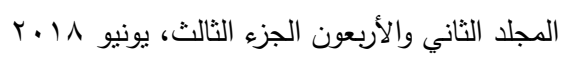


بالحياة سواء علي مستوى البيئة العالمية أو البيئة المصرية مما استوقف الباحثني لزيادة البحث عن آليات ووسائل تحد من هذا الخطر الذي بات يهدد الحياة علي الكرة الارضية إذ تعاني البيئة العالمية بشكل عام ومصر بشكل خاص من مشاكل جمة متعلقة بالبيئة وملوثاتها حيث أظهر تقرير وزارة البيئة ان عوادم السيارات احد المصادر الرئيسية المسبية لتلوث الهواء

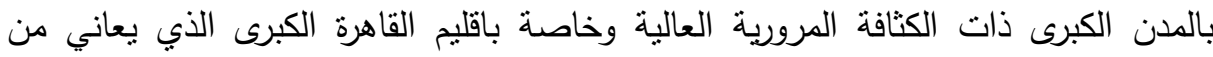
مشاكل واختتاقات مرورية نتيجة زيادة اعداد المركبات عن الطاقة الاستيعابية للطرق ، حيث اشارت دراسة اعدها المعهد القومي للنقل بالتعاون مع هيئة المعونة اليابانية (جايكا) ان

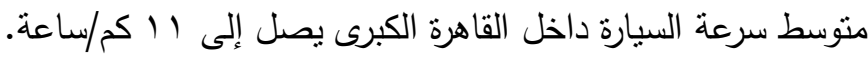
كما أشارت الدراسات التى قامت بها وزارة الدولة لثئون البيئة (تقرير وزارة البيئة

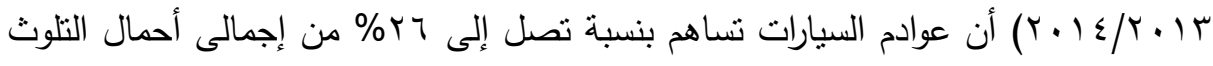

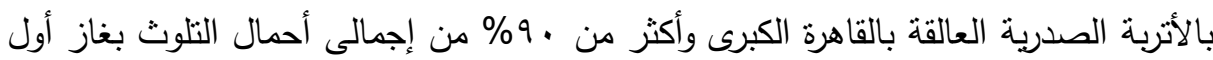
أكسيد الكربون و • 9\% من إجمالى أحمال التلوث بالهيدروكربونات و .0\% من إجمالى أحمال

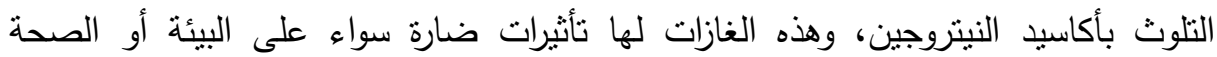

يعتبر قطاع النقل فى مصر هو المستهلك الرئيسى للمواد البنرولية حيث تصل نسبة استهلاكه للوقود البترولى ^r\% من إجمالى استهلاك الوقود فى مصر ، وتبلغ كمية السولار

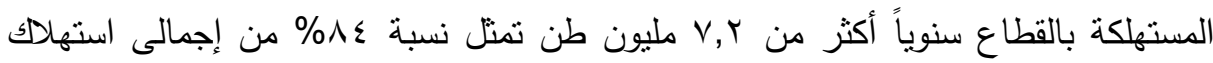

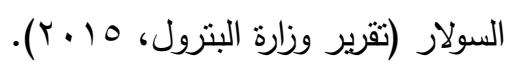
كما أوضح الرصد السنوي (تقرير الادارة العامة للمرور، 10 • ب) لأعداد المركبات زيادة

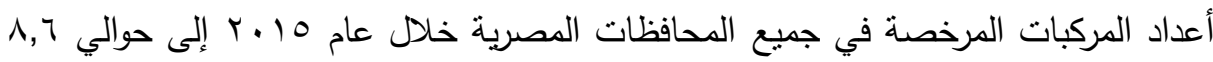

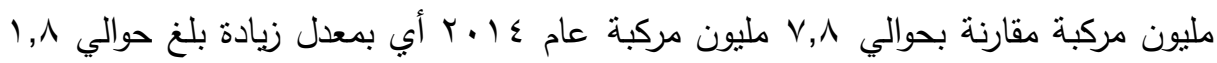

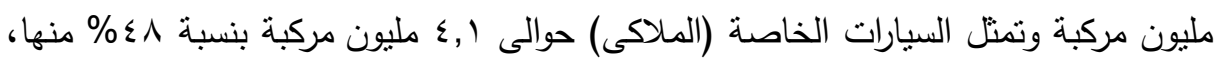

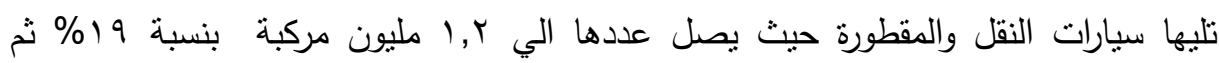

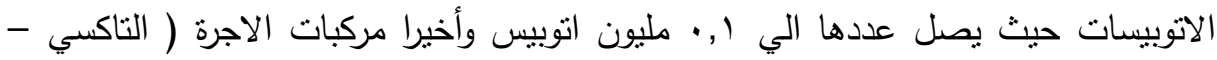

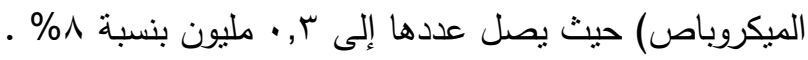

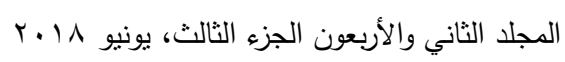


تزيد حدة مشكلة تلوث الهواء بعوادم السيارات نتيجة تقادم أسطول السيارات فى مصر وزيادة أعمارها وبقائها فى الخدمة بالرغم من انخفاض كفاءة محركات تللك السيارات وزيادة

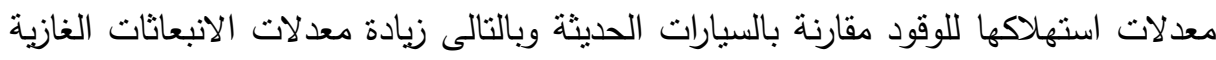

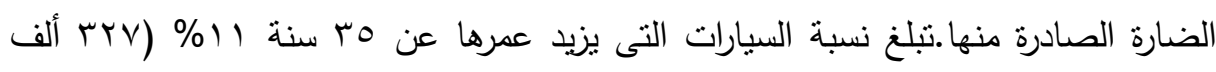
سيارة) من إجمالى السيارات المرخصة بمصر بينما نسبة السيارات التى تتراوح أعمارها بين

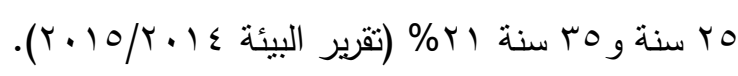

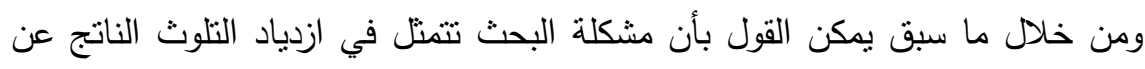

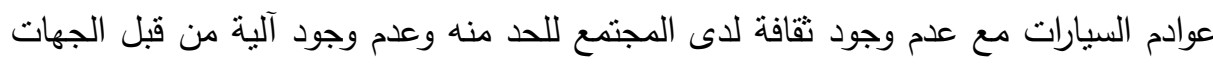
المعنية للحد من هذا التلوث بالاضافة الي عدم تتاسب تكلفة علاج ووقاية البيئة من هذا مناف

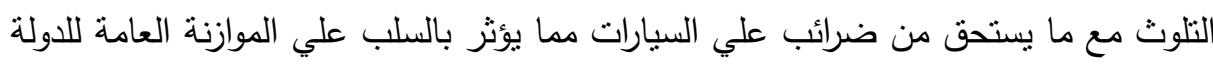

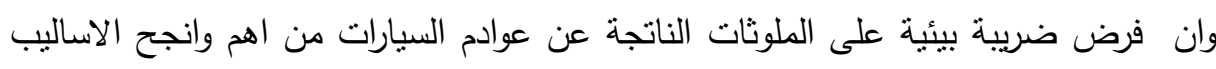

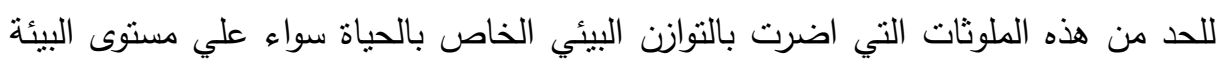
العالمية أو البيئة المصرية.

\section{أهسا أهث المهيه}

1- ايجاد العلاقة بين الضريبة البيئية كأحد الأدوات المالية وبين الحد من الملوثات البيئية وخاصة الناتجة عن عوادم السيارات بما يعظم أهداف مصلحة الضرائب والأهداف البيئية. r- رفع الوعي الضريبي في تحقيق أهداف اجتماعية وزيادة الاهتمام بالبيئة وملوثاتها لتوفير

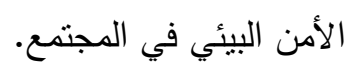

r- محاولة التوصل إلى نموذج مقترح لتطبيق الضريبة البيئية بما يخدم الاقتصاد القومي نظراً لأهمية مصلحة الضرائب المصرية. ع - تقديم مجموعة من التوصيات والمقترحات في ضوء نتائج الدراسة للحد من التلوث البيئي. 


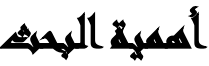

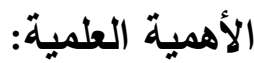

• نسليط الضوء علي أهية الضريبة البيئية كأحد أدوات السياسة المالية للحد من التلوث

$$
\text { الناتج عن عوادم السيارات. }
$$

• أن محاولة الكثف عن العلاقة بين الضريبة البيئية والايرادات السبادية بمثل محاولة

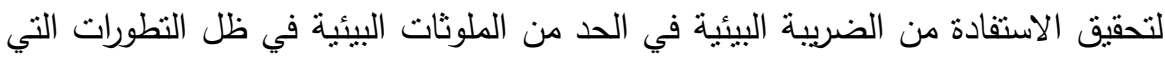

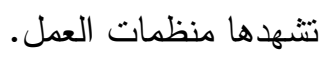
• نص في الكتابات والبحوث والدراسات التي تناولت بالدراسة والنحليل مفهوم الضرائب البيئية وتأثيرها في الحد من الملوثات الناتجة عن عوادم السيارات.

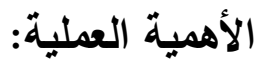

• من خلال هذا البحث يمكن أن نقيس مدي قدرة الضرائب البيئية علي الحد من الملوثات البيئية وخاصة الملوثات الناتجة عن عوادم السيارات.

• زيادة الإيرادات الضريبية واستخدام هذه الإيرادات المتأتية من هذا النوع من الضرائب في التيات

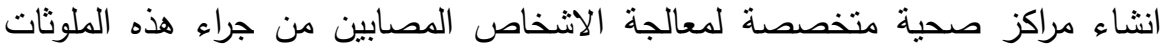

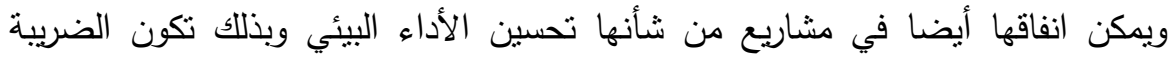
البيئية ساهدت بشكل كبير في الحد أو الإقلال من الملوثات البيئية.

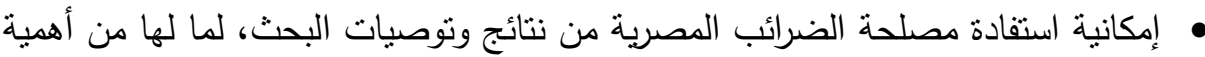
في تحقيق الاستقرار المالي والنمو الاقتصادي للوطن.

\section{هروضر الهبه}

ينطلق البحث لإثبات الفرضية الأساسية الآتية إنَ تطبيق الضريبة البيئية على الملوثات

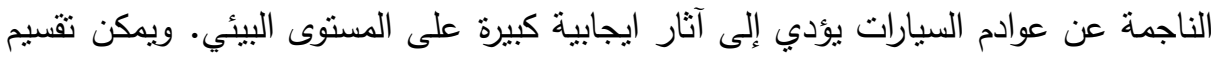
هذا الفرض الرئيسي إلي الفروض الفرعية الآتية: 
مجلة العلوم البيئية

معهز الدراسات والبحوث البيئية - جامعة عين شمس لهن

يوجد تأثنير ايجابي ذو دلالة احصائية للضريبة البيئية على الحد من الملوثات الناجمة عن

$$
\text { عوادم السيارات. }
$$

هوجد تأثير ايجابي ذو دلالة احصائية للحوافز الضريبية على الحد من الملوثات الناجمة

$$
\text { عن عوادم السيارات. }
$$

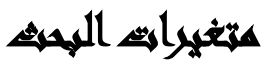

بناء على الفروض التي نم تتاولها في البحث يكون المتغير المستقل هو (الضريبة

$$
\text { البيئية) والمتغير التابع هو (الملوثات الناجمة عن عوادم السيارات). }
$$

\section{aty}

مصلحة الضرائب المصرية - السيارات العاملة في مصر .

\section{الصراسايت المايهية}

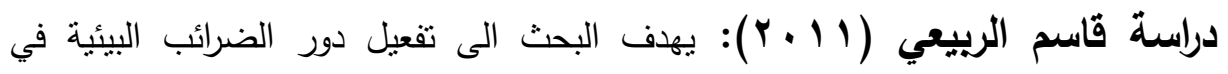
معالجة الملوثات الناتجة عن عوادم السيارات، وبناء نموذج مقترح والية عمل لفرض الضريبة

$$
\begin{aligned}
& \text { البيئية على السيارات في العراق. } \\
& \text { وتوصلت الدراسة إلى: }
\end{aligned}
$$

• إن مسؤولية حماية البيئة واجب على كل من (الفرد والمجتمع والحكومة) بصورة منساوية

$$
\text { أي حماية البيئة واجب الكل. }
$$

إن ربط الضرائب البيئية المفروضة على السيارات الملوثة للبيئة بأغراض وأهداف بيئية

$$
\text { محددة مسبقا يجعل هذه الضرائب مقبولة لدى أغلب المواطنين. }
$$

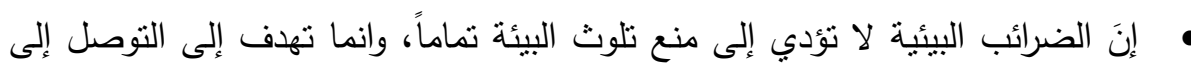

الحجم الأمنل للتلوث أو الحد المقبول والمعياري من الأذى البيئي. 
دراسة كامل القيناوي (ع ا ب r): وهدفت إلى:

إلقاء الضوء علي الدور الذي يمكن أن يلعبه النظام الضريبي بمختلف أدواته في التأثثر

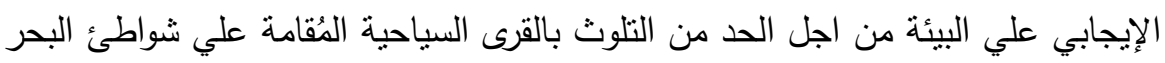

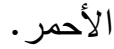

ه اقتراح تفعيل دور الضرائب الخضراء للحد من التلوث البيئي من خلد الاستفادة بأهم أدوات الحوافز الضريبية المتمنلة في الإعفاء الضريبي أو الإهلاك المعجل.

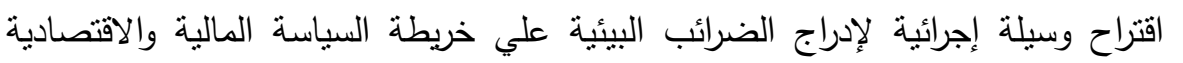
للاولة المصرية بشكل مرن لضمان نجاحها في الحد من التلوث بالقرى السباحية.

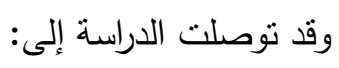

• توجد علاقة ذات دلالة احصائية بين قيمة الضرائب علي الارباح المحصلة من القرى السياحية الملوثة للبيئة والتي تدرج ضمن ايرادات الموازنة العامة للدولة وتكاليف علاج

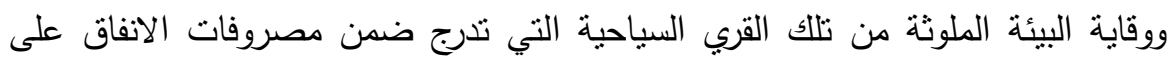
حماية البيئة بالموازنة العامة للدولة. توجد علاقة جوهرية بين ضرورة استخدام الحوافز الضريبية ضمن أدوات الضرائب الخضراء وبين الحد من التلوث البيئي النابع عن القري السياحية. توجد علاقة ذو دلالة احصائية بين اتجاه المجتمع لفرض ضرائب بيئية للحد من التلوث البيئي بالقري السياحية وعدم تفعيل التشريعات البيئية.

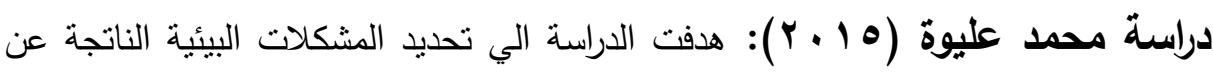
الصناعات الملوثة للبيئة بكثافة بالتطبيق على صناعة الاسمنت في مصر. الكثف عن المخاطر التي تحدث نتيجة لتلوث الهواء من شركات صناعة الاسمنت. اظهار أهمية الحوافز

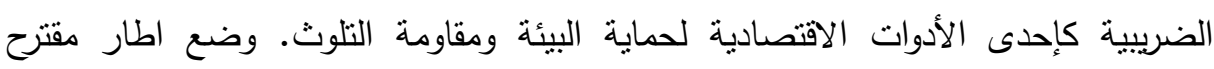
للحوافز الضريبية بهدف تخفيض التلوث بالتطبيق على شركات الاسمنت. وتوصلت الدراسة إلى ان مستويات التلوث فى مصر قد نعدت الحدود القصوى المسموح بها دوليا بدرجات عالية الخطورة وان فرض ضريبة على التلوث قد يودى الى زيادة إيرادات

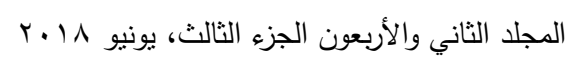


الدولة وقد نوجه جزء منها او كل هذه الإيرادات للإنفاق على مكافحة التلوث او علاج اثأر

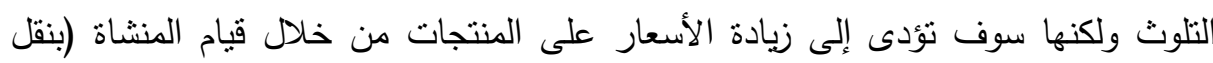
عبء الضريبة) إلى المستهلك النهائي. دراسة نيفين كمال (10 ( Y ): تهدف هذه الورقة إلى تحديد مدى حاجة مصر إلى تطبيق

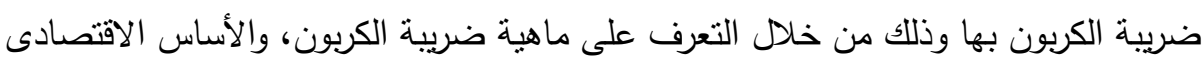

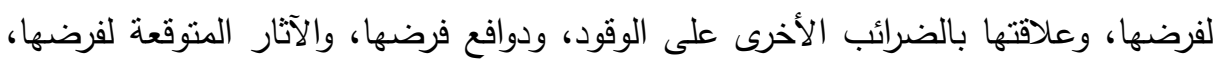

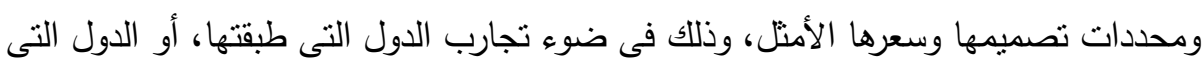
فى الطريق إلى تطبيقها. وتوصلت الورقة إلى : • أهمية فرض ضريبة الكربون فى مصر بشروط معينة، وذللك لأهميتها الكبيرة بيئياً فى الحد من ظاهرة تغير المناخ ذات الاهتمام الدولى المتزايد، بالإضافة إلى عوائدها المالية وندية التى قدرتها بعض الدراسات بقيمة لايستهان بها.

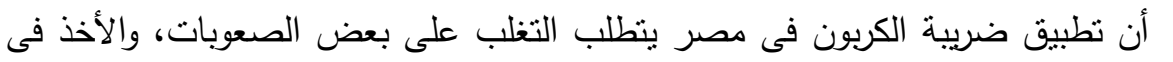

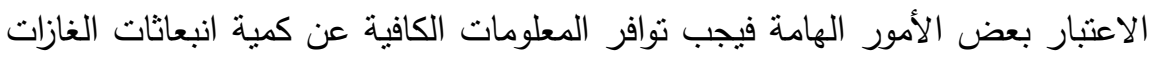

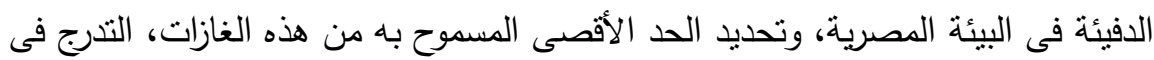

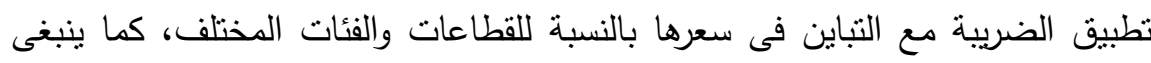

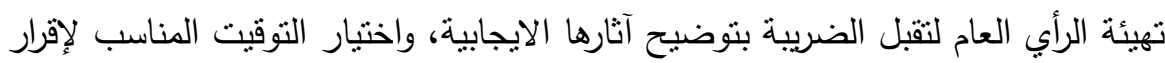

$$
\text { فرض الضريبة. }
$$

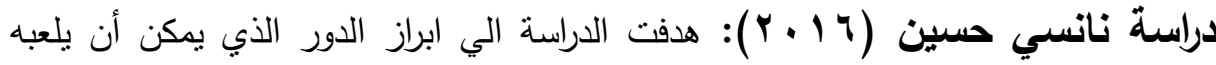

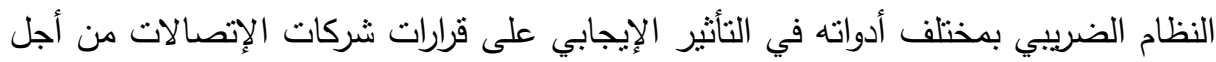

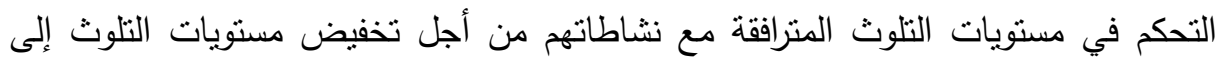


وتوصلت الدراسة إلى:

• وجود علاقة واضحة وايجابية بين تفعيل النظام الضريبي البيئي والحد من التلوث

الكهرومغناطيسي في مجال الاتصالات.

• وجود علاقة واضحة وكبيرة بين انعدام الوعي الضريبي البيئى وزيادة وتعمق المشاكل

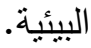

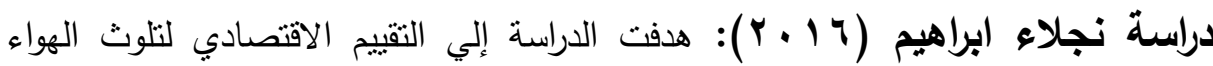
بعوادم السيارات وذللك من خلال تحقيق الأهداف الفرعية الآتية: •بناء اطار فكري لتلوث الهواء لعوادم السيارات واسباب حدوثها والتعرف على التأثيرات السلبية وذللك بالتعرف علي المؤشرات. عرض الآتار الاقتصادية الناتجة عن معالجة مؤشرات نلوث الهواء بعوادم السيارات. • وضع نموذج مقترح للحد من نلوث الهواء لعوادم السيارات.

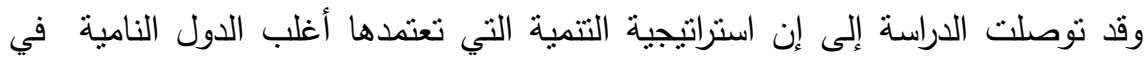

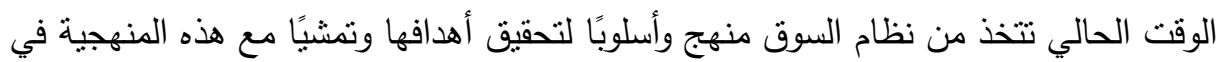
إدارة الاقتصاد فإن الاعتماد على مدخل السوق في معالجة مشاكل التلوث البيئي يعد مدخلا استيراتيجيا وبالتالي فإن الخيار الضريبي الذي يؤدي إلي فرض الضرائب علي التلوث ومظاهر الأذي البيئي الأخري كفيل بأن يدفع الأفراد والمنشآت الملوثة والمجتمع ككل ليدركوا

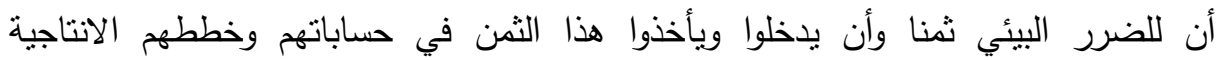

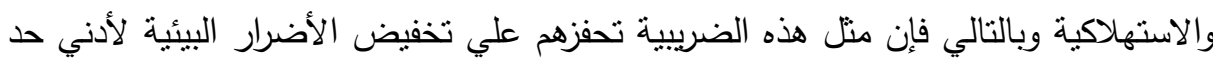

أوجه التشابه مع الدراسة الحالية: تتمثل اوجه التشابه بين الدراسات السابقة والدراسة الحالية في ان الدراسة الحالية تربط بين الضريبة البيئية ودورها في الحد من الملوثات الناتجة من

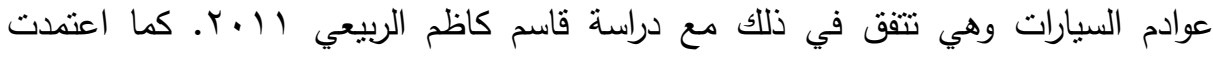
الدراسة الحالية علي تقسيم الملوثات الناتجة عن عوادم السيارات والتي تشمل ثاني اكسيد 
الكبريت، ثاني اكسيد الكربون، الجسيمات الكلية العالقة، الرصاص، اكاسبد النيروجين وتأثير

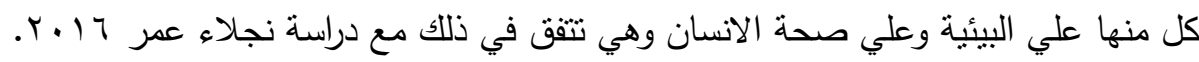

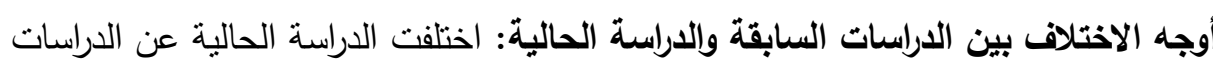
السابقة في مجال التطبيق حيث ربطت بين تأثنر الضريبة البيئية في الحد من ملوثات السيارات ويمثل مجال التطبيق السيارات العاملة في مصر وبين تأثيرها علي الجهة المنوطة بالنطبيق وهي مصلحة الضرائب المصرية وما تؤدي اليه الضريبة البيئية من زيادة في ايرادات

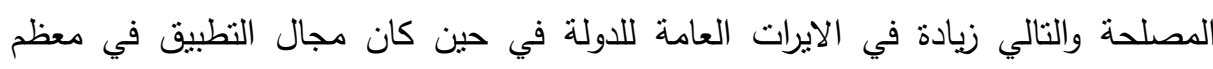
الدراسات السابقة الصناعات البترولية وصناعة الاسمنت والقرى السياحية ولم تتتاول عوادم

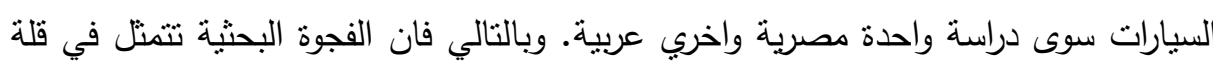

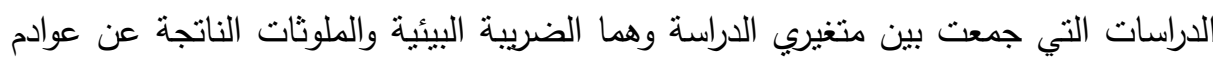

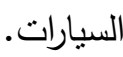

\section{الإطار المنظليه}

الضريبة البيئية (ضريبة التلوث): الضريبة البيئية هي إحدى وسائل التخخل الحكومي

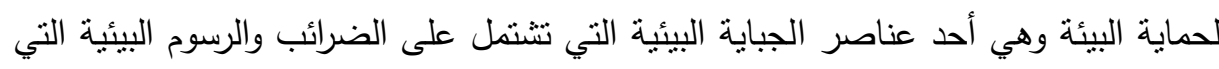

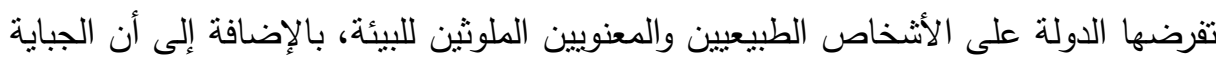

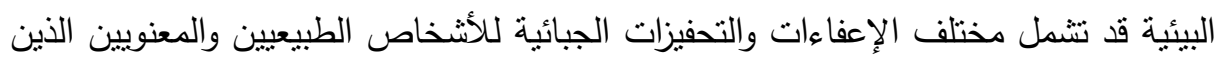
يستخدمون في نشاطاتهم الاقتصادية تقنيات صديقة للبيئة (عبد الباقي محمد، 9 × . ب).

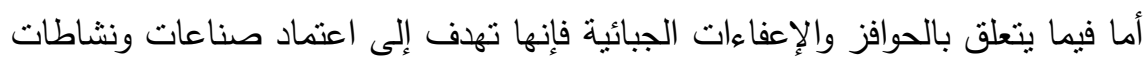

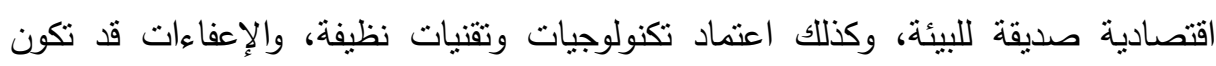

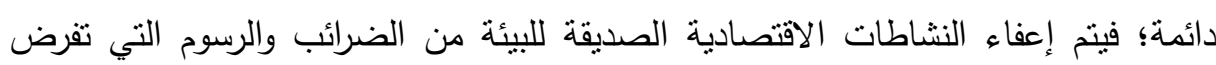

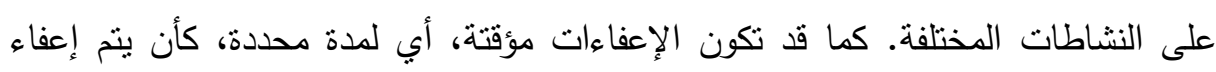

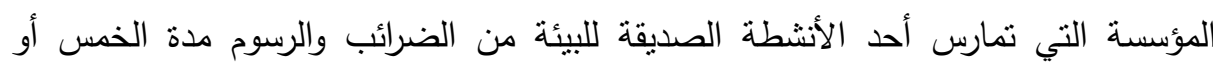
العشر السنوات الأولى لمباشرة نشاطها لتشجيعها على استخدام تكنولوجيا صديقة للبيئة، 
وكذلك لمساعدتها بشكل غير مباشر في إنتاج سلع أقل تكلفة من السلع التي تتنجها مؤسسات تستخدم تكنولوجيا ملوثة للبيئة، وأما الحوافز فتكون مثنا من خلال إعفاء المعدات والآلات المستوردة الصديقة للبيئة من كافة الضرائب والرسوم الجمركية.

تعريف الضريبة البيئية: الضريبة في ظل الفكر المالي الحديث سلاح مهم، وأداة من أدوات التنخل لمواجهة العديد من المشكلات التي نواجه الدول؛ إذ يمكن استخدامها لحماية المنتجات

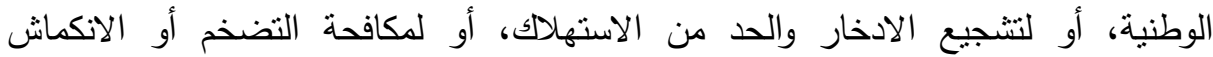
الاقتصادي، أو لتقليل التفاوت بين الدخول والثروات، لـأ. إلخ. يعرفها البعض بأنها عبارة عن اقتطاع نقدي يتناسب مع حجم الانبعاثات الفعلية أولي

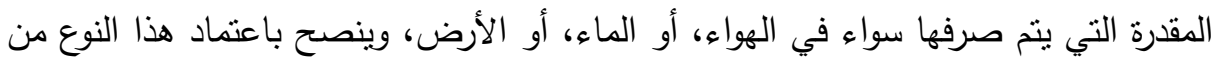

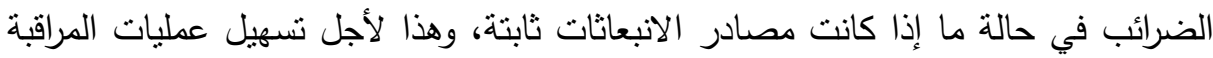

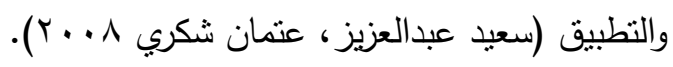

كما يعرف البعض الآخر الضريبة البيئية بأنها عبارة عن “اقتطاع إجباري، يدفعه الممول

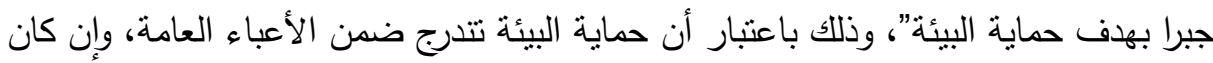

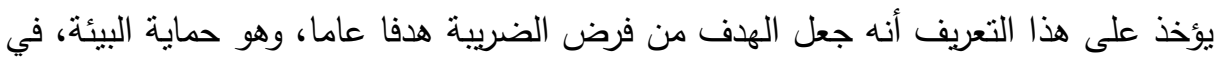
حين أن الهذف من فرضها هو جبر الضرر الذي ألحقه الممول (الملوث) بالبيئة، وهذا يبرر فرض الضريبة على الملوث بالذات دون غيره، أما مسئولية حماية البيئة فهي مسئولية مشتركة

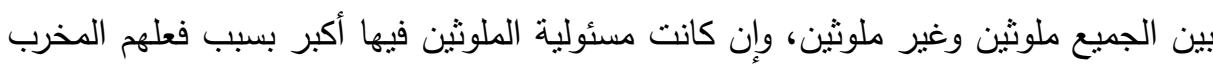
(عز الدين ابراهيم، بو (199) ).

كما عرفت منظمة التعاون والتتمية الاقتصادية (Organization for Economic) Co-operation and Development "OECD”) بدون مقابل يتم تحصيلها لحساب الخزانة العامة ويكون فرضها بسبب ارتباط وعائها بالبيئة

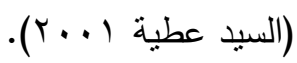
وتبعا لما تقدم وترتيبا عليه يمكننا أن نعرف الضريبة البيئية بأنها تعني قيام المكلف بالضريبة (الملوث) بدفع مبلغ من المال جبرا وبدون مقابل وبصفة نهائية إلى الدولة نتيجةً

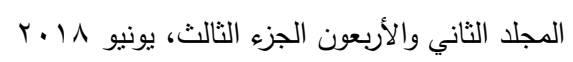


لإنتاج سلعة أو تقديم خدمة تزيد من تلويث البيئة، وهذا المبلغ يكون مساويا للتكلفة الحدية

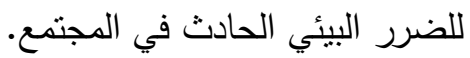

مبادئ الضريبة البيئية: في العديد من دول العالم خاصة الدول المتقدمة التي اعتمدت سياسات بيئية للحد من الملوثات ارتكزت هذه السياسات على مجموعة من المبادئ وهي

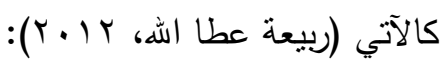

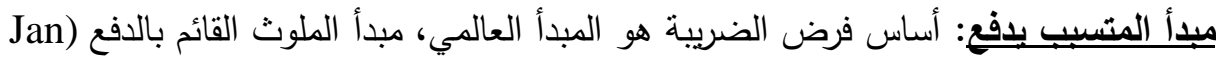
Stenis, and William Hogland 2003):

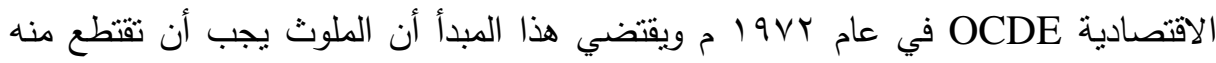
السلطات العمومية النفقات الخاصة بالإجراءات الرامية إلى الحفاظ على البيئة في حالة مقبولة

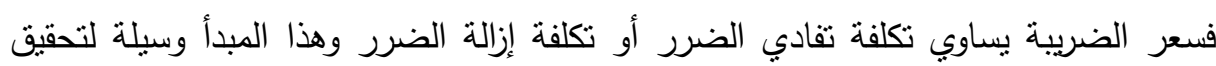

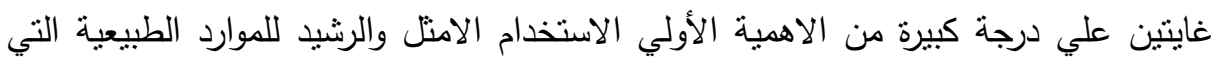
تحتويها البيئة، والثانية تحديد وتقليص نسبة التلوث (Sharon Beder, 2006). مبدأ العبع الجماعي: تتحمل السلطة العامة التكاليف البيئية للحد من الأضرار البيئية بشكل مباشر, أو غير مباشر بدلا من المتسبيين للتلوث في حالة عدم أمكانية تحديد المنسبب للتلوث أو في الحالات الطارئة التي يتوجب معالجتها من قبل الدولة.

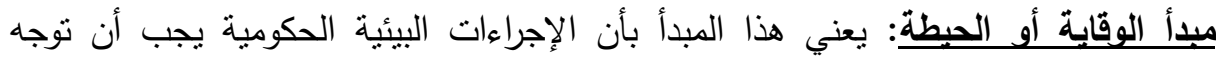
لحماية المرتكزات البيئية وإعطائها الأولوية من أجل حماية الوجود البشري وفقا لمبدأ الوقاية خير من العلاج. مبدأ المشاركة والتعاضد: تعتبر المسؤولية جماعية ومشتركة للفعاليات الإقتصادية المعنية بتخريب البيئة والإضرار بها، من خلال المشاركة في تخطيط وتتفيذ الإجراءات اللازمة لحماية البيئة للوصول إلى علاقات منوازنة بين الحرية الفردية والحاجات والمصالح الاجتماعية.

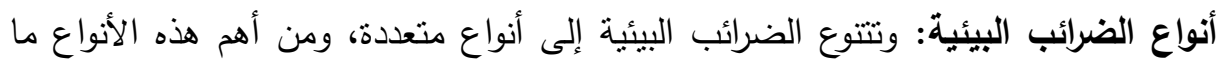


•الضريبة على المنتجات: هي ضريبة قيمية أو نوعية على الإنتاج في مختلف الوحدات الإنتاجية التي يصاحب إنتاجها أو نشاطها تلوث البيئة أي إحداث أضرار اجتماعية، وذلك الته بهدف تخفيض حجم الإنتاج، ومن ثم تخفيض حجم الملوثات الناتجة إلى المستويات

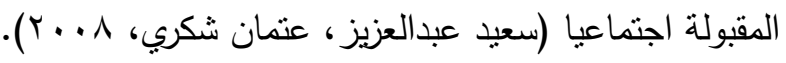

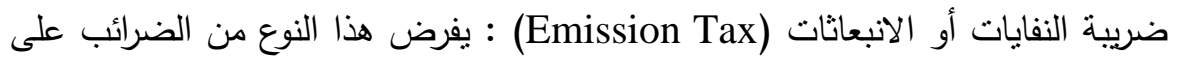
مختلف النشاط الإنتاجي للوحدات الاقتصادية، كما انها تمارس دور الأسعار السوقية للتكلفة الخارجية للتلوث، فهي تعكس قيمة الآثار الخارجية السلبية الناجمة عن تشغيل المشروعات الملوثة للبيئة، ووفقا لهذه الضريبة يسعى المنتجون إلى تخفيض الانبعاثات

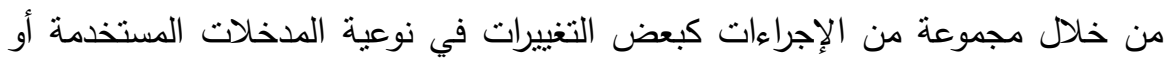

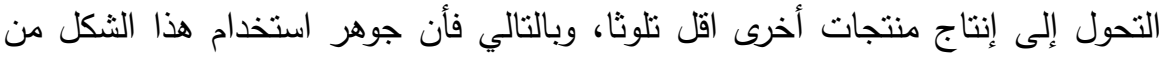
الضريبة هو إعطاء الحرية للمنتج الملوث للبيئة في البحث واختيار الطريقة الملائمة لتخفيض حجم الانبعاثات الملوثة للبيئة إلى مستويات مقبولة. ولكن يعاني فرض ضريبة النفايات من الصعوبات التالية: - انها تسمح بالوصول الى حجم الانتاج مع مستويات التلوث الى مسنويات منلى اجنماعياً

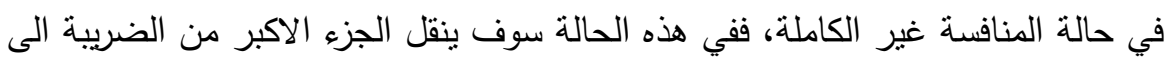
المستهلكين دون الاهتمام بمعالجة النفايات طالما ان المستهلك هو الذي يتحمل العبء

$$
\text { الاكبر من هذه الضريبة. }
$$

- الجمود وعلم المرونة حيث ان فرض ضريبة موحدة على كل وحدة من وحدات التلوث

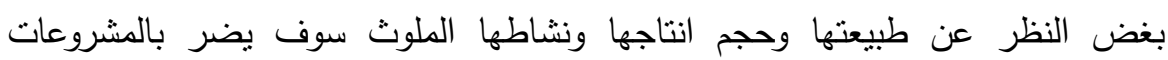

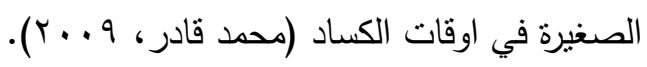

• ضريبة الكربون (Carbon Tax) : وهي ضريبة قديمة جدا، وقد تم فرضها لأسباب مالية بحتة وتفرض على أنواع الوقود: البترول، الوقود النفطي، زيت الديزل، الكيروسين، الغاز

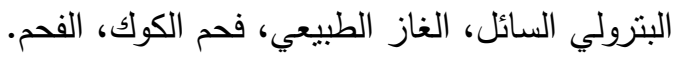
ضريبة النقل (Transportation Tax) : يتضمن هذا النوع من الضرائب كل من:

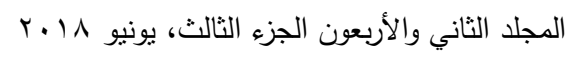


- ضريبة على بيع محركات السيارات: يفرض هذا النوع من الضرائب على استيراد السبارات،

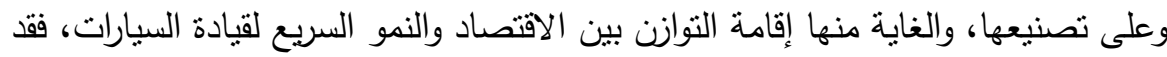

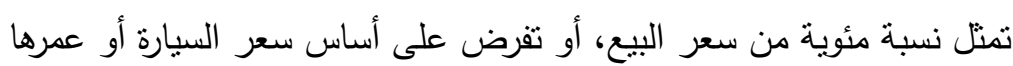

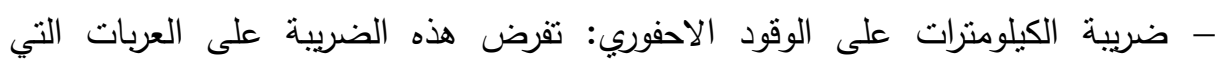
بالديزل، وتفرض كمجموع محدد لكل عشرة كيلو منرات، وتتدرج استتادا إلى نوع ووزن لهن لهنه السيارة الخاضعة للضريبة. - ضريبة محركات السيارات: هي ضريبة على مالك السيارة، تفرض بهدف جاعلي مالكي

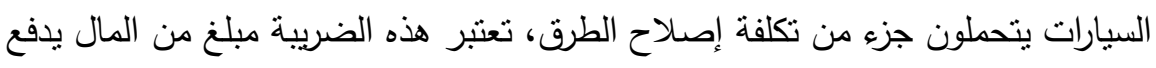

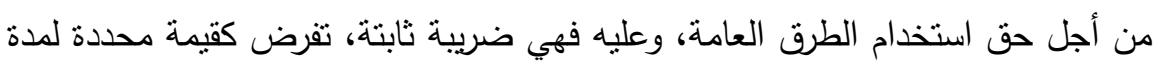

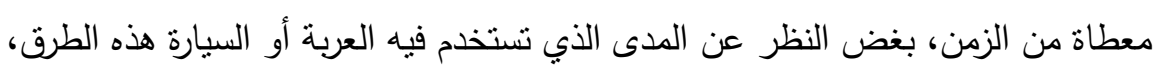
حجم الضريبة بعتمد على نوع السيارة، نوع الوقود، عدد عجلات الندي السيارة.

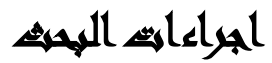

منهـج البحث: اعتمد الباحثون على المنهج الوصفي التحليلي لتحقيق أهداف البحث من

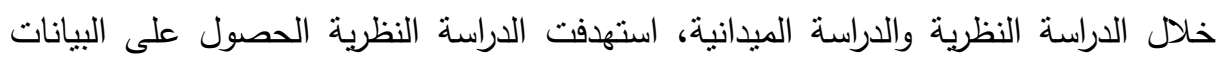

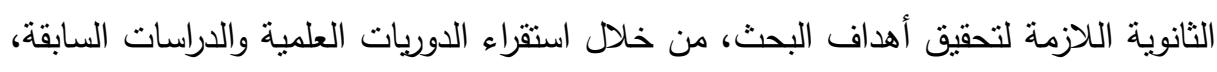

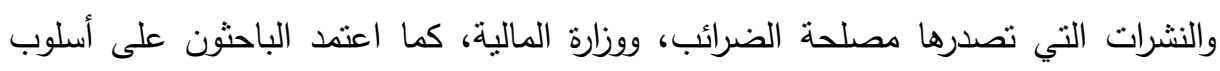

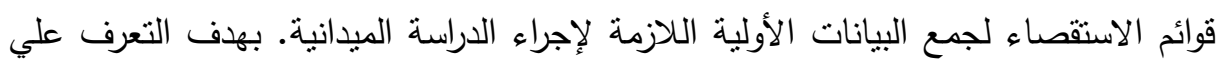
مدي فعاليه ما ينم اتخاذه حاليا من إجراءات لمكافحه تلوث البيئة في مصر ، وامكانية استخدام

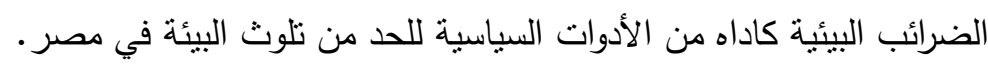
عينة البحث: تمنل مجتمع البحث في ثلاث فئات مختلفة هي: • فئة العاملين بالمصلحة الضرائب والذين يزيد عددهم على خمسين ألف، موزعين على فئى فئل

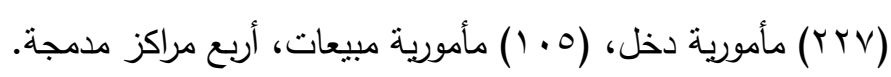


• فئة الإدارة العليا بالمصلحة منمنلة في (رؤساء المأموريات والمراكز المدمجة، المناطق الضريبة، القطاعات والإدارات المركزية)، والبالغ عددهم (OV乏) مفردة. فئة ممولي الضريبة علي السيارات بمصلحة الضرائب المصرية والذين يزيد عددهم عن

(IVVYTMT ( مليون ممول منتشرين على مستوى جميع محافظات الجمهورية. تحديد عينة البحث:

العينة الأولى: (العاملين) حجم العينة لمجتمع يزيد عن ( (...0) مفردة هي (rیץ) مفردة .

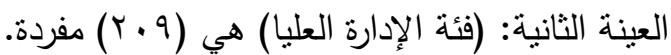
العينة الثالثة: (فئة الممولين) حجم العينة هي (عیى) مفردة. أدوات الاراسة: نم تصميم قائمة استقصاء والتي تتضمن قسمين: القسم الأول: موجهة للإدارة العليا، والعاملين ويحتوي على: - مجموعة من الفقرات وعددها (• (1) فقرات لـتغير التلوث البيئي ودور الأجهزة المعنية في مكافحة التلوث واسباب التلوث ودور الوعي البيئي في مواجهة التلوث الناتج عن عوادم السيارات. - مجموعة من الفقرات وعددها (·r) فقرة لمتغير الضريية البيئية ودورها في الحد من التلوث ويشمل (الاطار العام لفرض الضريية، نطاق الضريية، سعر الضريبة، حصيلة الضريبة البيئية، معوقات

$$
\text { فرض الضريية). }
$$

$$
\text { القسم الثاني: موجهة لممولي الضريبة ويحتوي على: }
$$

المحور الاول: يحتوى على مجموعة من الفقرات لقياس تتمية الوعي البيئي لدى الممولين. المحور الثاني: يحتوى على مجموعة من الفقرات لقياس مدى فعالية الاجراءات الحالية

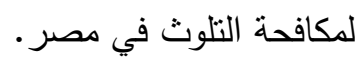
المحور الثالث: يحتوى على مجموعة من الفقرات لقياس استخدام السياسة الضريبية لمكافحة

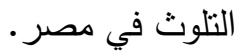
المحور الرايع: يحتوى على مجموعة من الفقرات لقياس استمرار التعاون بين المصلحة والممولين. 
أساليب المعالجة الإحصائية المطبقة: قام الباحثون بالاعتماد البرنامج الإحصائي (SPSS22)، لتفريغ البيانات وجدولتها وإجراء التحليل الإحصائي المناسب لتحليل البيانات ولإختبار صحة فروض البحث، وتطلب ذلك تطبيق بعض أساليب الإحصاء الوصفي

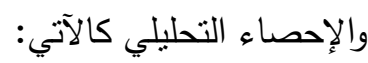
الإحصاء الوصفي: نم الاعنماد على الإحصاء الوصفي، الوسط الحسابي والانحراف المعياري

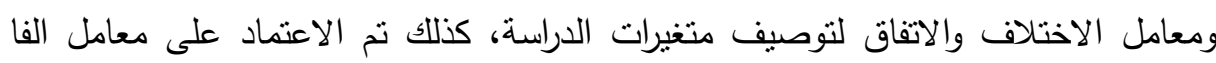

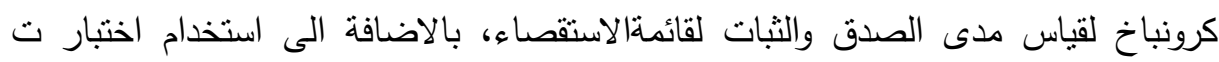
اللمجوعة الواحدة للتحقق من صحة فرض لهوب الدراسة. قياس صدق قوائم الاستقصاء: قياس الصدق الظاهري: قام الباحثّن بعرض القوائم على المشرفين، وعلى عدد من المحكمين، وعلى عدد من مفردات مجتمع البحث، بهدف التأكد من سلامة الصياغة الإجرائية

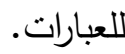

قياس الصدق والثبات لقوائم الإستقصاء: تم حساب معاملي الصدق والثبات لأسئلة الاستقصاء في كل فئة، وتبين أن معاملات الصدق والنبات مقبولة لأسئلة الاستبيان ككل، لأن جميع قيمة معاملى الصدق والثبات تجاوزت (V), ·)،وبالتالي يمكن القول أنها معاملات

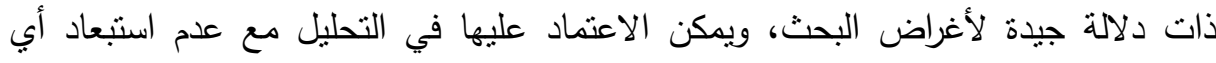
عنصر من عناصر المتغيرات محل الدراسة والجدول التالي يوضح ذللك: 
جدول ( 1): يوضح معامل الثبات والصدق لاستماره العاملين والادارة العليا

\begin{tabular}{|c|c|c|c|c|}
\hline \multicolumn{2}{|c|}{ الادارة العليا } & \multicolumn{2}{|c|}{ العاملين } & \multirow[b]{2}{*}{ البيان } \\
\hline المعلق & 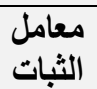 & الصدق معل & 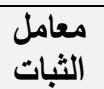 & \\
\hline$\cdot, \wedge \vee \varepsilon$ & $\cdot, \vee \vee \neg \varepsilon$ & $\cdot, 9.0$ & . & 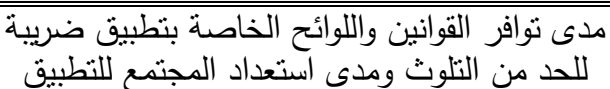 \\
\hline$\cdot, 97$. & $\cdot, 94$ & $\cdot, 971$ & $\cdot, 9 r \leq$ & اسباب ومميزات تطبيق نظام الضريبية البيئية علي \\
\hline$\cdot, \wedge \varepsilon \cdot$ & $\cdot, V \cdot \uparrow$ & 伿 & $\cdot, V \leqslant r$ & محددات نجاح او فثنل تطبيق الضريبة البيئية \\
\hline$\cdot$, , $० \mathrm{~V}$ & $\cdot, \mathrm{v}$ ro & •, & 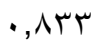 & كيفية نطبيق نظام الضريبة البيئية \\
\hline$\cdot, \mathrm{\vee} \wedge$. & $\cdot, 7 \cdot 1$ & $\cdot, 9.0$ & $\cdot, \wedge 19$ & التحديات التي تواجه تطبيق الضريبة البيئية \\
\hline$\cdot, 9 \leqslant 7$ & $\cdot, \wedge 90$ & • & $\cdot, 9$ P $^{\circ}$ & 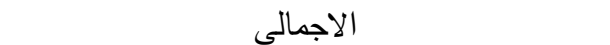 \\
\hline
\end{tabular}

جدول (r): يوضح معامل الثبات والصدق لاستمارة المولين

\begin{tabular}{|c|c|c|}
\hline معامل الصدق & معامل الثبات & البيان \\
\hline$\cdot, 9 \leq \vee$ & $\cdot, \wedge 97$ & تتمية الوعي البيئي لدى الممولين \\
\hline$\cdot, \wedge \vee \wedge$ & $\cdot, V \vee \varepsilon$ & مدى فعالية الاجراءات الحالية لمكافحة التلوث في مصر \\
\hline$\cdot, \wedge \vee r$ & $\cdot, \vee \vee 11$ & استخدام السياسة الضريبية في مجال مكافحة التلوث في مصر \\
\hline$\cdot, \wedge \vee \varepsilon$ & $\cdot, 1970$ & استمرار التعاون بين المصلحة والممولين \\
\hline$\cdot, 9 \leq 7$ & $\cdot, \wedge 90$ & الاجمالي \\
\hline
\end{tabular}


مجلة العلوم البيئية

معهز الدراسات والبحوث البيئية - جامعة عين شمس لهن

التحليل الوصفي للققرات الخاصة بالعاملين:

جدول (r): يوضح آراء عينة الدراسة من الادارة العليا والعاملين في مدى توافر القوانين واللوائح الخاصة بتطبيق ضريبة للحد من التلوث ومدى استعداد المجتمع للنطبيق التهاه

\begin{tabular}{|c|c|c|c|c|c|c|}
\hline \multicolumn{3}{|c|}{ العاملين (ن = r r r) } & \multicolumn{3}{|c|}{ الادارة العليا (ن =9 • r) } & \multirow[b]{2}{*}{ الفقرات } \\
\hline الاختلافف معامل & الانحراف & المتوسط المرجح & الاختلامل معام & الانحراف & المتوسط & \\
\hline $1 \varepsilon$, & $\cdot, 7 r$ & $\varepsilon, \varepsilon \Gamma$ & $1 \wedge, 1$ & $\cdot, \lambda)$ & $\varepsilon, \varepsilon \wedge$ & 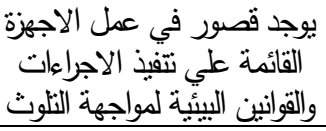 \\
\hline$r \varepsilon, \varepsilon$ & $\cdot, 97$ & r,qu & rq,0 & 1,10 & $r, q$. & 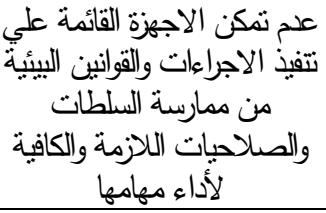 \\
\hline $17, \varepsilon$ & $\cdot,(\vee)$ & ( & $19, r$ & $\cdot, \wedge \varepsilon$ & $\varepsilon, \Gamma \wedge$ & الاقراد والمؤسسأت والمختى لدى ولفي \\
\hline 19,0 & $\cdot, \wedge$. & $\varepsilon, 1$. & $1 \wedge, 0$ & $\cdot, \vee \vee 9$ & $\varepsilon, \zeta \wedge$ & $\begin{array}{c}\text { الختتة القواعد والاجراءة بحماية البيئة بين } \\
\text { التدة قوانين }\end{array}$ \\
\hline$r\urcorner, V$ & $1, \cdot 1$ & $r, \vee q$ & $r \mu, \varepsilon$ & $\cdot, 90$ & $\varepsilon, \cdot 7$ & علم تضمين المناهج اللراسية \\
\hline $17, \cdot$ & $\cdot, 79$ & $\varepsilon, \Gamma$ & 11,9 & 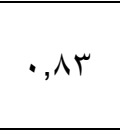 & $\varepsilon, r_{q}$ & 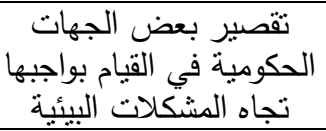 \\
\hline $1 \varepsilon, \Gamma$ & $\cdot, 7 \pi$ & $\varepsilon, \varepsilon 1$ & $1 T, 0$ & $\cdot, 71$ & $\{, 01$ & ضعف برامج التوعية البيئية \\
\hline $1 \wedge, r$ & $\cdot, \vee_{0}$ & $\varepsilon, 1 \Gamma$ & $M, \Lambda$ & $\cdot, 09$ & $\varepsilon, 7$. & عدم الالتزام بالقوانين \\
\hline 19,9 & $\cdot, \wedge$. & $\varepsilon, \cdot r$ & 17,1 & $\cdot, \mathrm{VO}$ & $\varepsilon, \varepsilon\rceil$ & بالثئون البيئية من سوء الجية الإنية \\
\hline
\end{tabular}

المصدر: من مخرجات البرنامج

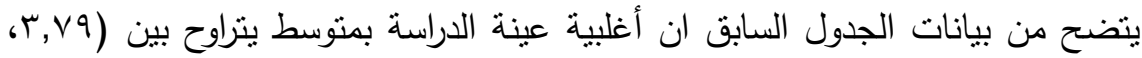

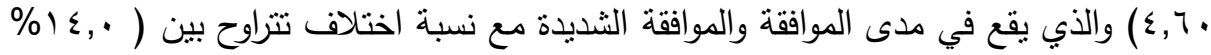

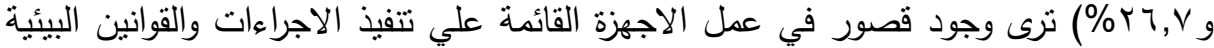
362

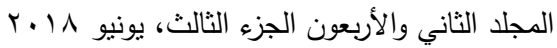


لمواجهة التلوث، ويرجع ذللك الى عدم تمكن الاجهزة القائمة علي تتفيذ الاجراءات والقوانين البيئية من ممارسة السلطات والصلاحيات اللازمة والكافية لأداء مهامها و معاناة الجهات المعنية بالشئون البيئية من سوء الادارة ، مع نتتت القواعد والاجراءات الخاصة بحماية البيئة بين عدة قوانين، كما يوجد تقصير لبعض الجهات الحكومية في القيام بواجبها تجاه المشكلات البيئية، مما يؤدي إلي ضعف فعالية مكافحة التلوث، ويرجع ذلك إلى ضعف برامج التوعية البيئية، عدم تضمين المناهج الدراسية الحالية موضوعات تتعلق بالتربية البيئية ، مع عدم البية الالتزام بالقوانين والنتشريعات البيئية. جدول رقم (؛): يوضح أراء عينة الدراسة من الادارة العليا والعاملين في أسباب ومميزات

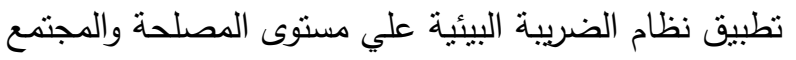

\begin{tabular}{|c|c|c|c|c|c|c|}
\hline \multicolumn{3}{|c|}{ العاملين (ن = آمر) } & \multicolumn{3}{|c|}{ 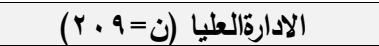 } & \multirow[b]{2}{*}{ الفقرات } \\
\hline الاختلاف & الانحراف & المتوسط & الاختلاف معلف & الانحراف & المتوجط & \\
\hline rı, & $\cdot, 91$ & $\varepsilon, 1 \wedge$ & $r \cdot, \Lambda$ & $\cdot, 9$. & ( & تطبيق (الملوث بدفع) البيئية ينطلق من \\
\hline $1 \cdot, 1$ & $\cdot, \mathrm{V} \leq$ & $\varepsilon, 1$ & $r \cdot, r$ & $\cdot, \wedge 9$ & $\varepsilon, \Gamma q$ & والاقتصادية والبيئية بين السياسات المالية \\
\hline$Y \uparrow, Y$ & 1,1 . & $\varepsilon, 1 r$ & $r \cdot, \cdot$ & $\cdot, \wedge \wedge$ & $\varepsilon, r q$ & 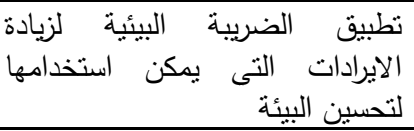 \\
\hline$r \uparrow, \wedge$ & $1, \cdot 1$ & $\varepsilon, \cdot r$ & $r \cdot, \Lambda$ & $\cdot, 9$ & ( & 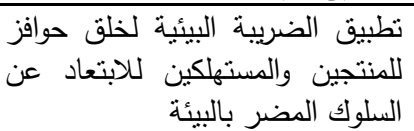 \\
\hline$r \uparrow, 1$ & $1, \cdot r$ & $r, 90$ & $r 0, r$ & $1, \cdot 1$ & $\varepsilon, Y V$ & نسهم الضربية البيئية في زبادة فعالبة الييئة. \\
\hline 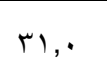 & 1,10 & $r, v)$ & $r \uparrow, r$ & 1,11 & $\varepsilon, Y \leq$ & نسهر الضريبة البيئية في زيادة الكفاءة \\
\hline$r \varepsilon, 0$ & $1, \cdot 1$ & $\varepsilon, 1 \Gamma$ & r r & $\cdot, 97$ & $\varepsilon, \Gamma$ & 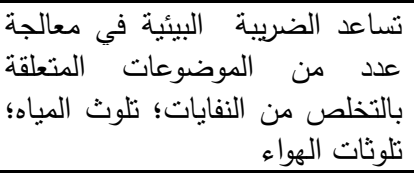 \\
\hline rq, ६ & $1,1 r$ & $\Gamma, \wedge)$ & $r v, 0$ & 1,10 & $\varepsilon, 19$ & تضاهم الضريية البيئية في زبادة الحصيلة \\
\hline$r_{0, \Lambda}$ & $\cdot, 90$ & $r, 79$ & $r \varepsilon, \wedge$ & $1, \cdot 1$ & $\varepsilon, \cdot \wedge$ & تيادةالثفافية الضريبة $\quad$ البيئية فى \\
\hline
\end{tabular}

المصدر : من مخرجات البرنامج

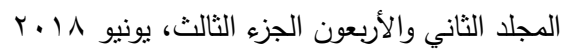


يتضح من بيانات الجدول السابق ان أغلبية عينة الدراسة بمتوسط يتراوح بين (9, ب,،

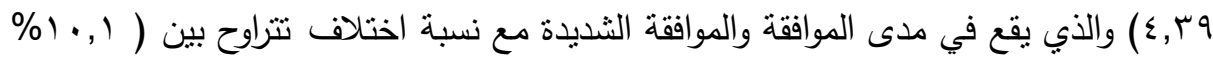
و •, اسT\%) ترى من وسائل تخفيف الأضرار البيئية نطبيق الضريبة البيئية وينطلق من مبدأ

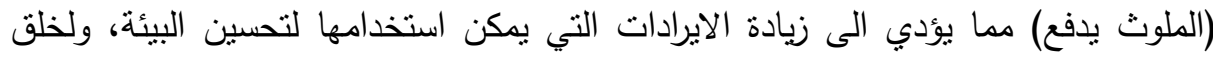
حوافز للمنتجين والمستهكين للابتعاد عن السلوك المضر بالبيئة مما يسهم في زيادة فعالية البيئية وزيادة الكفاءة الإقتصادية، مما يخلق دمج بين السياسات المالية والاقتصادية والبيئية، وأن الضريبة البيئية تساعد في معالجة التخلص من النفايات الناتجة عن؛ تلوث المياه؛ تلونات الهواء، كما تساهم في زيادة الحصيلة الضريبية، وزيادة الثفافية. جدول رقم (•): يوضح أراء عينة الدراسة من الممولين في تتمية الوعي البيئي لدهرم (rی⿱一⿻上丨)

\begin{tabular}{|c|c|c|c|c|c|}
\hline الاتجاه & الاتفاق & 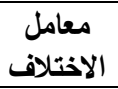 & المعياري & المتوسط المرجط & الفقرات \\
\hline موافق & ג, גד & M & $1, \pi r$ & $r, T V$ & 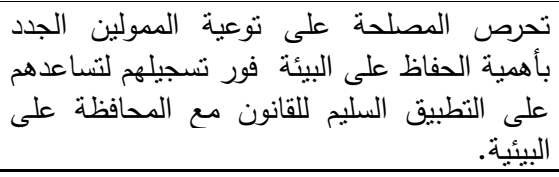 \\
\hline موافق & $T, T$ & rV, $\varepsilon$ & $1, r \varepsilon$ & r,Oᄉ & 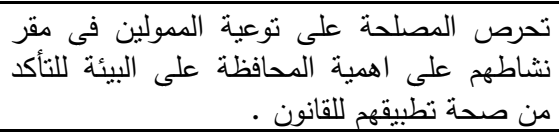 \\
\hline موافق & $70, V$ & $r \leqslant, r$ & $1, r V$ & $r, v$. & 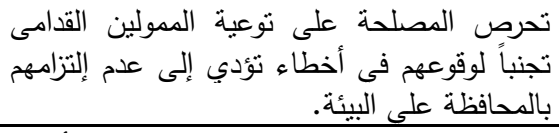 \\
\hline محايد & $4 \cdot \Lambda$ & $r q, r$ & $1, r r$ & $r, r V$ & 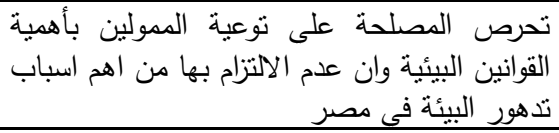 \\
\hline موافق & $V Y, \cdot$ & $\langle\wedge,$. & $1,1 \varepsilon$ & $\varepsilon, \cdot \Lambda$ & 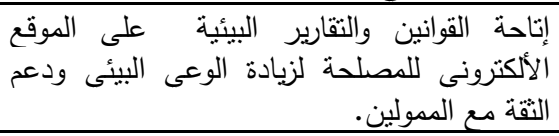 \\
\hline موافق & 79,9 & $r \cdot, l$ & $1, r_{0}$ & $\{, 17$ & الإستمرار في تنتية الإلعام المخيلفة. البيئي لدى الممولين \\
\hline
\end{tabular}


يتضح من بيانات الجدول السابق ان أغلبية عينة الدراسة بمتوسط يتراوح بين (r,r,r،

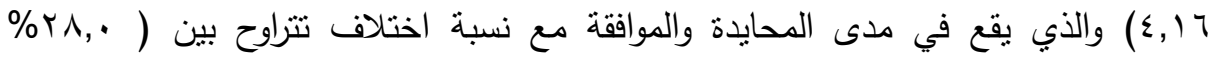

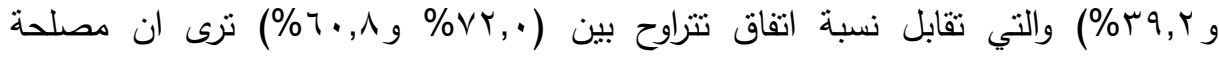
الضرائب تحرص على توعية الممولين الجدد بأهمية الحفاظ علي البيئة فور تسجيلهم لتساعدهم على التطبيق السليم للقانون مع المحافظة علي البيئية، حيث تقوم بتوعيتهم في مقر لترفي نشاطهم للتأكد من صحة تطبيقهم للقانون، كما تحرص على نوعية الممولين القدامى تجنياً لوقوعهم في أخطاء تؤدي إلى عدم إلتزامه بالمحافظة علي البيئة، وتحرص على نوعية

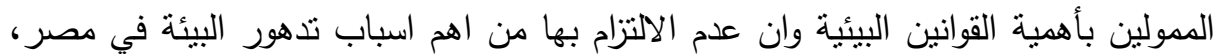
وأن إتاحة القوانين والثقارير البيئية على الموقع الأكتروني للمصلحة لزيادة الوعي البيئي ودعم الثقة مع الممولين، وان الإستمرار في تتمية الوعي البيئي لدى الممولين من خلال وسائل

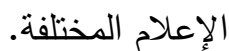

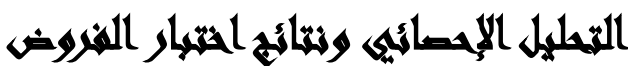

اختبار صحة فروض البحث:

الفرض الأول: يوجد تأثير ايجابي ذو دلالة احصائية للضريبة البيئية على الحد من الملوثات الناجمة عن عوادم السيارات، لاختبار الفرض قام الباحثون باستخدام تحليل

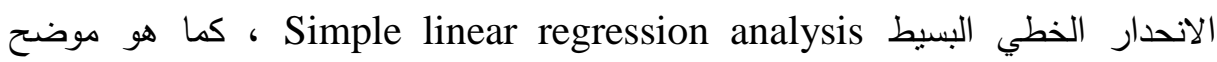
بالجداول أرقام (0)،(7).وقام الباحثون بعرض نتائج الفرض في كل فئة على حدى كالتالي:

أولاً: فئة الإدارة العلبيا:

المتغبر التابع: الحد من الملوثات الناجمة عن عوادم السيارات

المتغيرالمستقل: الضريبة البيئية

- وجود علاقة ارتباطية دالة احصائياً بين الضريبة البيئية والحد من الملونات الناجمة عن عوادم السيارات، حيث بلغت قيمة معامل الارتباط TVA, · عند مستوى دلالة أقل من الناطيه 
- معنوية نموذج الانحدار،حيث بلغت قت قيمة "ف" 9 . , IV7 عند مستوى دلالة أقل من

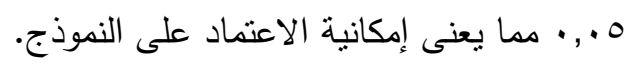

- إن الضريبة البيئية نؤثز على الحد من الملوثات الناجمة عن عوادم السيارات بمقدار \% \% \% V \% \%, V

$$
\text { لم تذكر في النموذج أو للخطأ العشوائي. }
$$

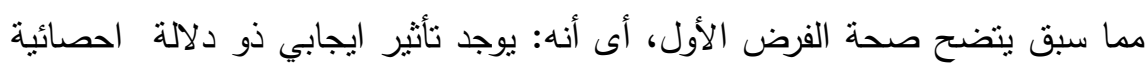

$$
\text { للضريبة البيئية على الحد من الملوثات الناجمة عن عوادم السيارات النصات }
$$

ثانياً: فئة العاملين:

$$
\text { المتغير التابع: الحد من الملوثات الناجمة عن عوادم السيارات }
$$

المتغبر المستقل: الضريبة البيئية

- وجود علاقة ارتباطية دالة احصائياً بين الضريبة البيئية والحد من الملونات الناجمة عن

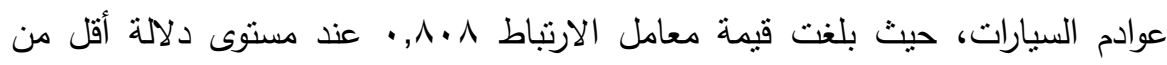
$\cdot, .0$

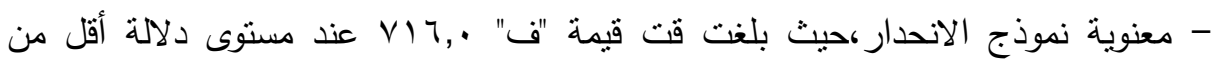

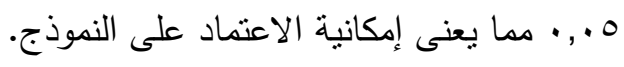

- من خلال قيمة معامل التحديد نجد ان الضريبة البيئية تؤثنز على الحد من الملوثات الصعات

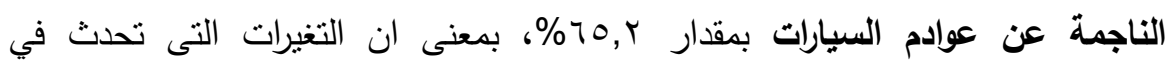

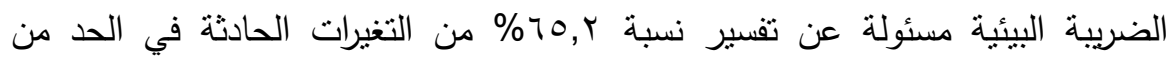

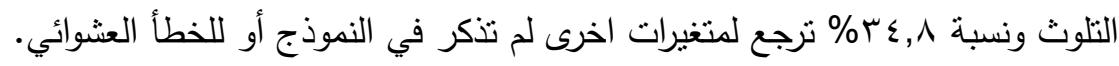

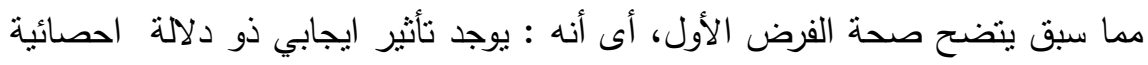

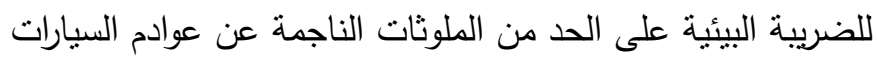




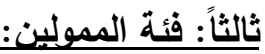

المتغبر التابع: الحد من الملوثات الناجمة عن عوادم السيارات

المتغبر المستقل: الضريبة البيئية

- وجود علاقة ارتباطية دالة احصائياً بين الضريبة البيئية والحد من الملوثات الناجمة عن

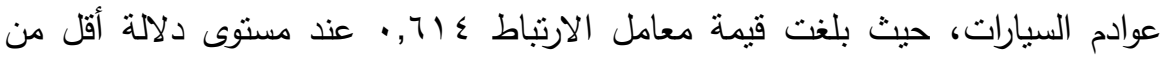
$\cdot, .0$

- معنوية نموذج الانحدار ،حيث بلغت قت قيمة "ف" ر, •rr عند مستوى دلالة أقل من

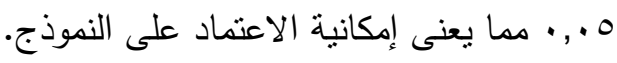
- ان الضريبة البيئية تؤثر على الحد من الملوثات الناجمة عن عوادم السيارات بمقدار TrV,T

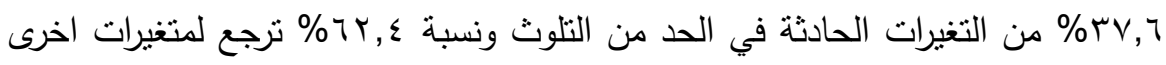
لم تذكر في النموذج أو للخطأ العشوائي. مما سبق يتضح صحة الفرض الأول، أى أنه : يوجد تأثير ايجابي ذو دلالة احصائية

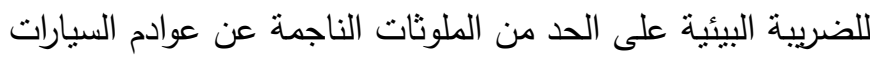
الفرض الثاني: يوجد تأثير ايجابي ذو دلالة احصائية لاستخدام الحوافز الضريبية ضمن

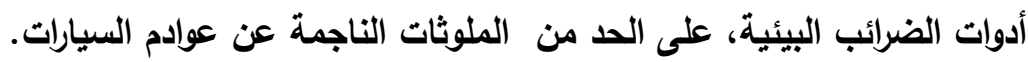

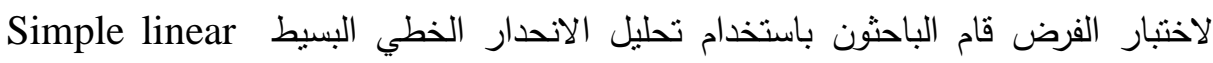

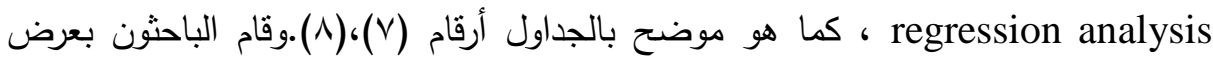
نتائج الفرض في كل فئة على حدى كالتالي: أولاً: فئة الإدارة العلبيا: المتغير التابع: الحد من الملوثات الناجمة عن عوادم السيارات المتغير|لمستقل: الحوافز الضريبية - وجود علاقة ارتباطية دالة احصائياً بين الحوافز الضريبية والحد من الملونات الناجمة عن

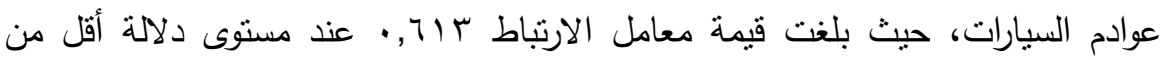
$\cdot, .0$

$$
\text { المجلد الثاني والأربعون الجزء الثالث، يونيو 11 بـ }
$$




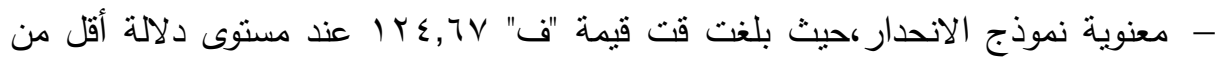

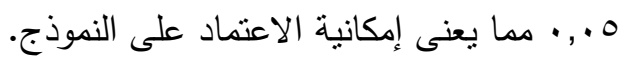

- ان الحوافز الضريبة تؤثز على الحد من الملوثات الناجمة عن عوادم السيارات بمقدات الندار

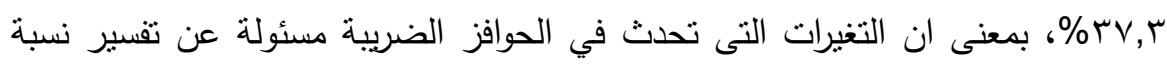

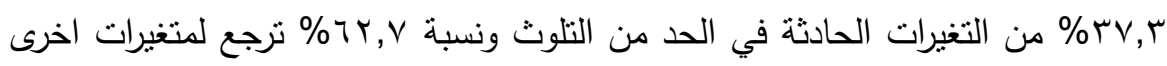
لم تذكر في النموذج أو للخطأ العشوائي.

مما سبق يتضح صحة الفرض الثاني، أى أنه : يوجد نأثير ايجابي ذو دلالة الحصائية لاستخدام الحوافز الضريبية ضدن أدوات الضرائب البيئية، على الحد من الملوثات النيح الناجمة

$$
\text { عن عوادم السيارات }
$$

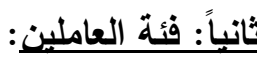

المتغير التابع: الحد من الملوثات الناجمة عن عوادم السيارات

المتغبر المستقل: الحوافز الضريبية

- وجود علاقة ارتباطية دالة احصائياً بين الحوافز الضريبية والحد من الملوثات الناجمة عن النئية

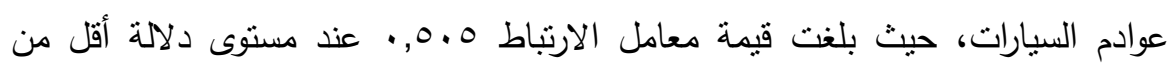
$\cdot, 0$

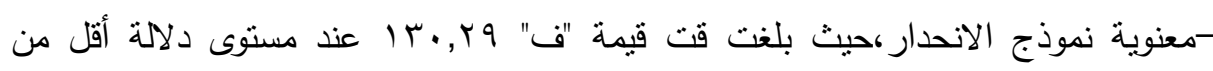

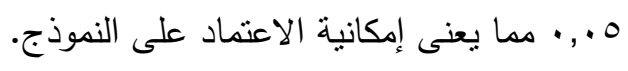

-إن الحوافز الضريبة نؤثز على الحد من الملوثات الناجمة عن عوادم السيارات بمقدار

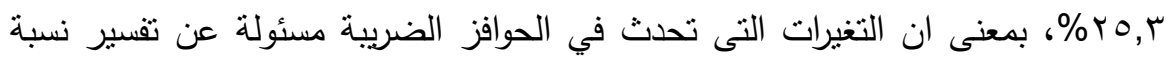

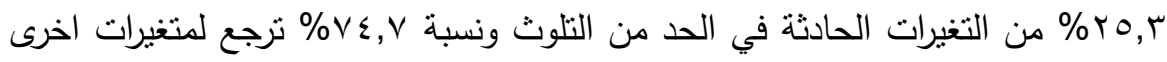

$$
\text { لم تذكر في النموذج أو للخطأ العشوائي. }
$$

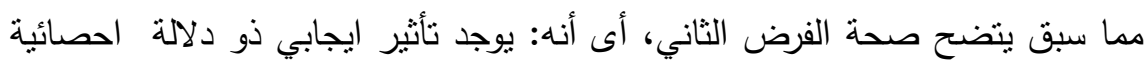

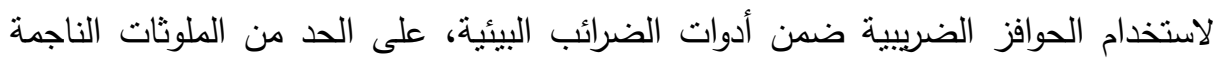
عن عوادم السيارات 


\section{تهمسير النمائية}

توصل الباحثون إلى مجموعة من النتائج المتعلقة بجانب البيئة وملوثاتها، والضرائب

البيئية التي يمكن تلخيصها بال|آتي:

- يوجد تأثير ايجابي ذو دلالة إحصائية للضريبة البيئية على الحد من الملوثات الناجمة

$$
\text { عن عوادم السيارات. }
$$

- يوجد نأثثر ايجابي ذو دلالة إحصائية لاستخدام الحوافز الضريبية ضمن أدوات الضرائب

$$
\text { البيئية، على الحد من الملوثات الناجمة عن عوادم السيارات. }
$$

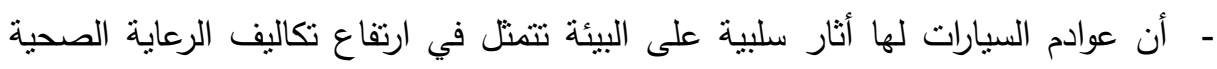

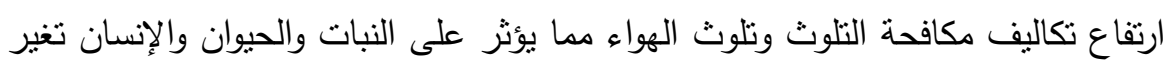

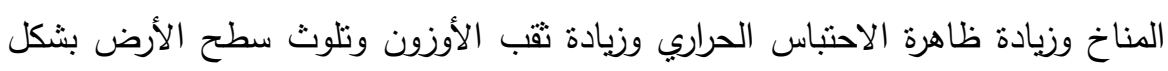

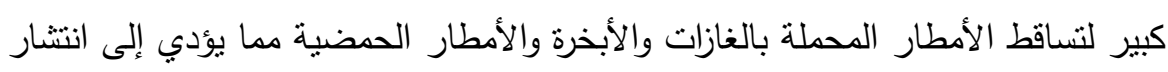

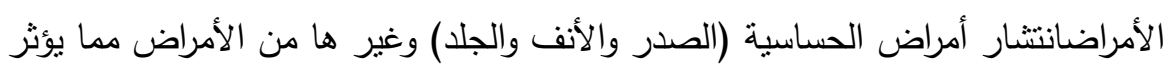

$$
\text { على إنتاجية العامل. }
$$

- أن أهم مشكلات تطبيق الضريبة البيئية تتمثل في القصور في خبرات وكفاءة العاملين بالأجزة القائمة على تتفيذ الإجراءات والقوانين والقصور في التشريعات البيئية وعدم فاعلية الإجراءات والقوانين البيئية كما يرى البعض من عينة الدراسة أن من مشاكل تطبيق الضريبية البيئية الخلاف حول تحديد تاريخ استحقاق الضريبة وحول تحديد وعاء الضريبة

وعدم اكتمال نظام الخصم الضريبي وعدم وعي الأفراد والمؤسسات بدور الضريبة البيئة.

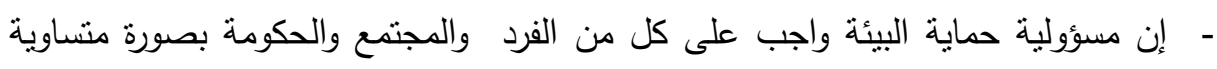
أي حماية البيئة واجب الكل.

- - مإن ربط الضرائب البيئية المفروضة على السيارات الملوثة للبيئة بأغراض وأهداف بيئية محددة مسبقا يجعل هذه الضرائب مقبولة لدى اغلب المواطنين.

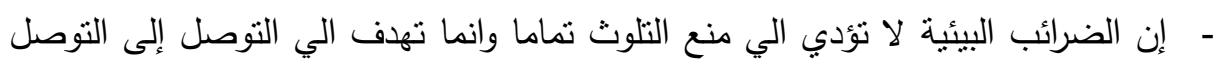
إلى الحجم الامثل للتلوث او الحد المقبول والمعياري من الأذى البيئي.

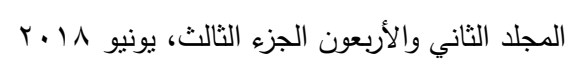


مجلة العلوم البيئية

معهد الدراسات والبحوث البيئية - جامعة عين شمس البه

- إن تطبيق هذا النوع من الضرائب يتطلب إصلاح ضريبي شامل ضمن خطة بعيدة المدى

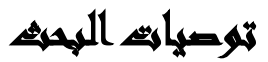

- الاهتمام بالتربية البيئية في جميع مراحل التعليم العام والعالي من أهم دعائم الأمن البيئي

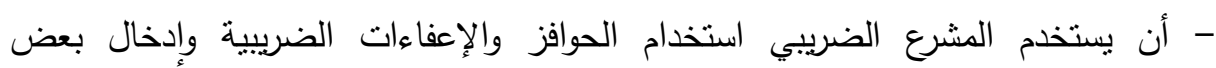

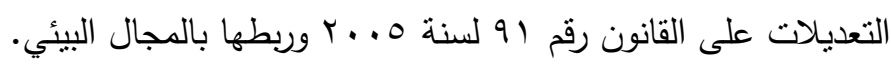
- تفعيل القوانين واللوائح البيئية لنطبيق مفهوم "الملوث يدفع الثن "بدلا من تحميل الخسائر

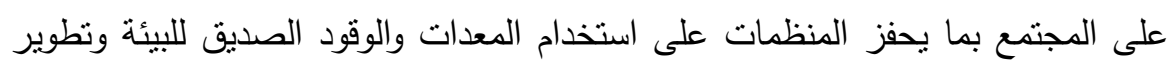

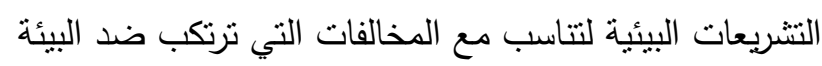
- التوعية بالمشكلات البيئية عن طريق وسائل الإعلام المختلفة، والمؤتمرات والندوات بصورة

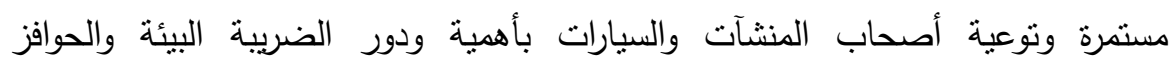
والإعفاءات التي تتالها الشركات التي تستخدم المعدات والوقود الصديق للبيئة. - ضرورة تعاون جميع قطاعات الدولة وأفراد المجتمع من أجل المحافظة على البيئة. - تحسين مواصفات وقود الديزل بخفض نسبة الكبريت واستخدام التكنولوجيا النظيفة بيئيا في

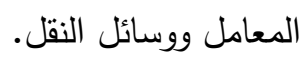

- متابعة المشكلات التي يفرزها تطبيق الضرائب البيئية المقترحة، والعمل على سد كل الثغرات التي تظهر أثناء التنفيذ. - ايداع المبالغ المحصلة من الضرائب البيئية في صندوق حماية البيئة في وزارة البيئة لغرض نفراه إنفاقها في مشاريع تحسين بيئية. - يجب أن تستند هيكلة التخفيض الضريبي على مستوى الانبعاثات ونوع الوقود المستخدم.

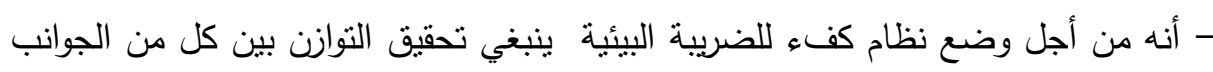
البيئية والمالية، وأن يهنم الإصلاح الضريبي بالآثار المالية والصحية والبيئية لضرائب البيئة وذللك لمساعدة واضعي السياسات على تحديد الأولويات بين بدائل الإصلاح 
المختلفة، حيث يؤدى فرض ضريبة بيئية علي السيارات إلي التحول بين الأنواع المختلفة من الوقود بم يحقق مزيج أفضل بيئيا.

\section{sall}

أحمد الفرج العطيات(997) (1): البيئة الداء والدواء، دار المسيرة للنشر والتوزيع والطباعة:

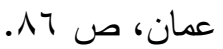

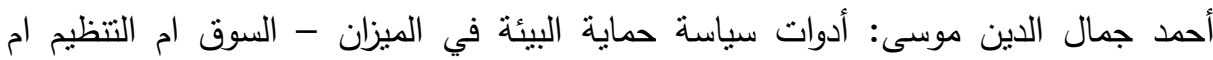

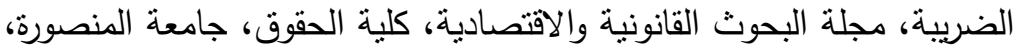

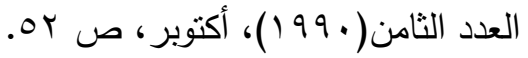

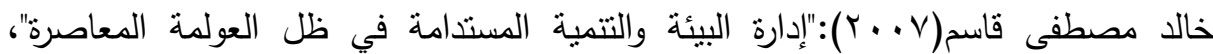

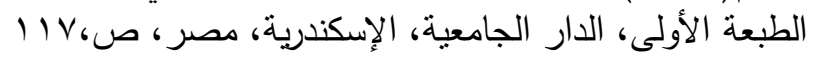

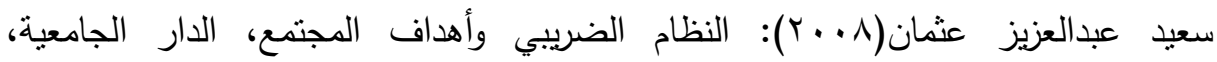
الإسكندرية.

السيد عطية عبد الواحد: الضريبة البيئية (ماهيتها- أنواعها- آثارها)، مجلة العلوم القانونية

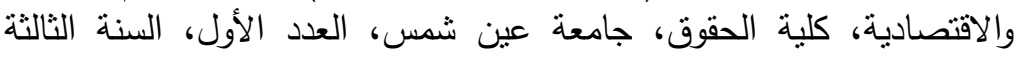

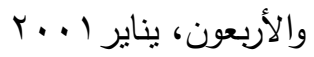

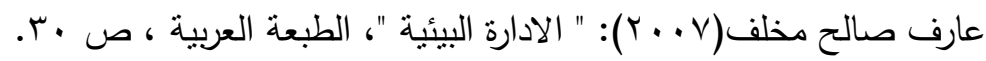

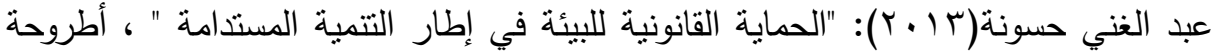

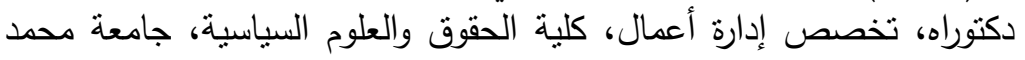

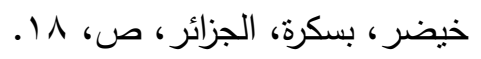

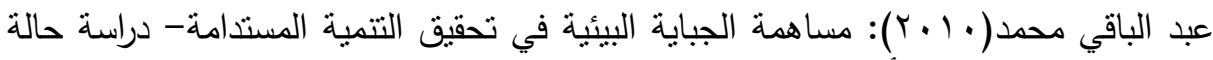

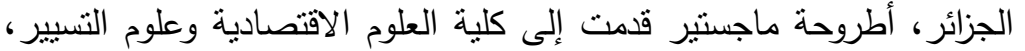

$$
\text { جامعة الجزائر }
$$

عز الدين إبراهيم: الضريبة على الكربون وحماية البيئة، مجلة العلوم القانونية والاقتصادية، العدد الثاني، السنة الخامسة والثثلاثون، يوليو برانة الينة، 199

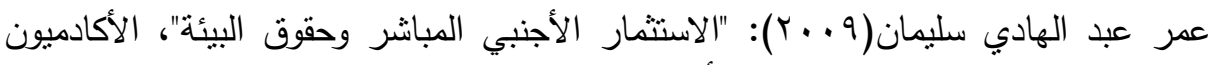

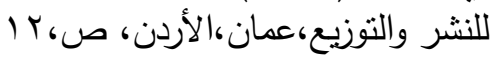

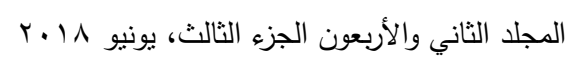


مجلة العلوم البيئية

معهد الدراسات والبحوث البيئية - جامعة عين شمس لبه

فارس مسدور: أهمية تدخل الحكومات في حماية البيئة من خلال الجباية البيئية، مجلة

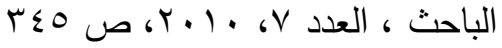

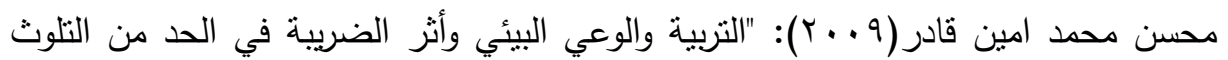

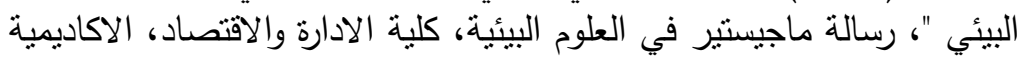

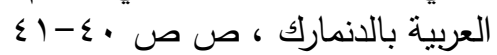

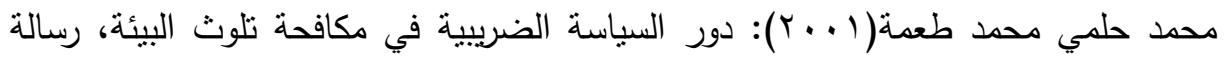

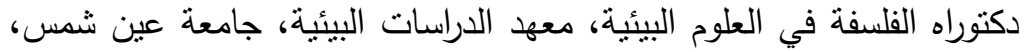
ص صك ماه

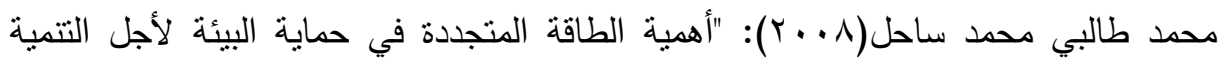

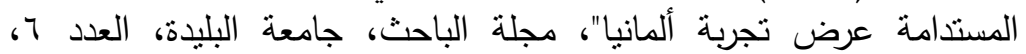

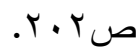

محمد عبد الباقي(· ( • ( ): "مساهمة الجباية البيئية في تحقيق التتمية المستدامة دراسة حالة

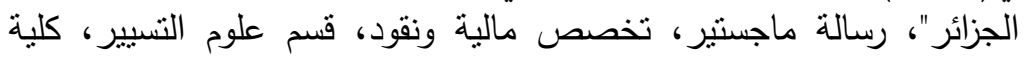

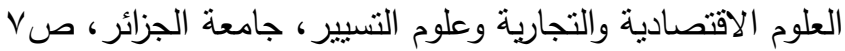

محمد عبد البديع(9V0 ()): "|قتصاد حماية البيئة"، دار الثروق، لبنان، ص 9.

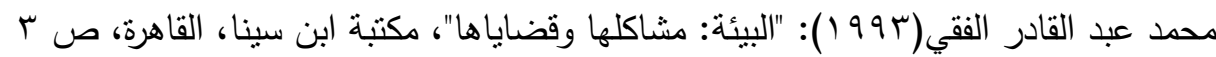
محمد عرفة: "الاهمية الاقتصادية للضريبة البيئية"، الجريدة الاقتصادية عدد .؟.ب

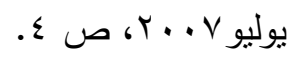

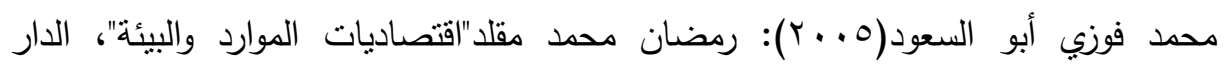

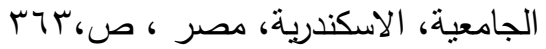

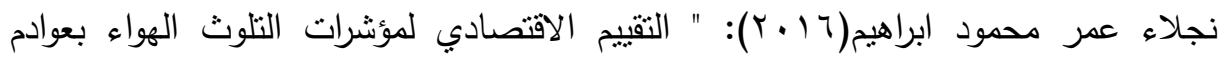

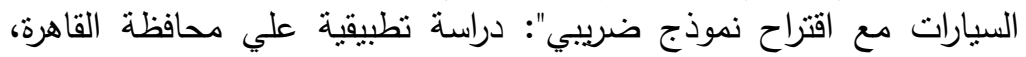

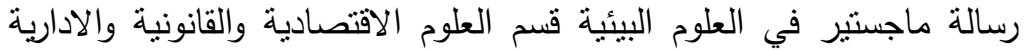

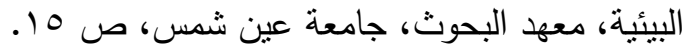

Agnar Sandmo, 2006, The Public Economics of the Environment, Oxford University Press, New York, p105.

Bohme, Peter and Bjorn Larsen ,2010, Fairness in a Tradable Permit Treaty for Emission Reductions in Europe and the farmer

Soviet Union In Peter Bohme the Economics of

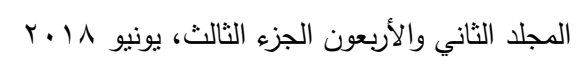


أحمد فؤاد مندور وآخرون

Environmental Protection theory and Demand Revelation Published by Edward Elgar UK.

J. Andrew Hoerner and Benoî t Bosquet,2001, Environmental Tax Reform (The European Experience), Center for sustainable economy, Washington, DC, February, p. 17.

J. Andrew Hoerner and Benoît Bosquet,2003, op.cit, p. 25.

Jan Stenis, and William Hogland, 2003, The Polluter-Pays Principle and its Environmental Consequences for Industrial Waste Management ,Environment, Development and Sustainability 4: Kluwer Academic Publishers, Netherlands, p. 362.

Jane Holder and Maria Lee,2007, Environmental Protection, Law and Policy, Text and Materials, Second Edition, Cambridge University Press, New York, p. 423

John Norregaard, Valérie Reppelin-Hill,2000, Controlling Pollution Using Taxes and Tradable Permits, International Monetary Fund, Economic Issues No. 25, December, p. 20.

Jordan Andrew, Wurzel Rüdiger, Zito Anthony,2003, New Instruments of Environmental Governance - National Experiences and Prospects, Routledge, p. 3.

José Marcos Domjngues, 2001, Environmental Protection - Tax System and Green Taxes - Brazil and Japan - Problems in Common, p. 21.

Kristine Kern, Helge Jörgens, and Martin Jänicke ,2001, The Diffusion of Environmental Policy Innovations" A Contribution to the Globalization of Environmental Policy" Discussion Paper FS II 01 - 302, Berlin, p. 20.

Kristine Kern, Helge Jörgens, and Martin Jänicke,2001, The Diffusion of Environmental Policy Innovations" A Contribution to the Globalization of Environmental Policy" Discussion Paper FS II 01 - 302, Berlin, p. 20.

$$
\text { المجلد الثاني والأربعون الجزء الثالث، يونيو 1 \ـ }
$$


Margaret Rosso Grossman, 2007, Agriculture and the Polluter Pays Principle, vol.11.3 Electronic journal of comparative law, December, p.3

Paul Ekins, 1999, Survey -European environmental taxes and charges recent experience, issues and trends, Ecological Economics, 31, ,p. 39-62, www.elsevier.com:locate: ecolecon.

Sharon Beder ,2006,: Environmental principles and policies - an interdisciplinary introduction, First published, the University of New South Wales Press, p. 33

\title{
THE USE OF ENVIRONMENTAL TAX TO REDUCE POLLUTANTS FROM CAR EXHAUSTS IN EGYPT - FIELD STUDY
}

Mandor, A. F. ${ }^{(1)}$; El Saed,E. M. $^{(1)}$ and Abdelbast, Hala, $\mathbf{R}^{(2)}$ 1) Faculty of Commerce, Ain Shams University 2) Egyptian Tax Authority

\begin{abstract}
The environment in general and Egypt in particular suffer from great problems related to the environment and its pollution. The report of the Ministry of Environment showed that car exhaust is one of the main sources of air pollution in large cities with high traffic density, especially in Greater Cairo, which suffers from traffic problems and congestion due to the increase in the number of vehicles on energy The problem of air pollution is exacerbated by the exhaust of cars due to the aging of the fleet of cars in Egypt and the increase in age and survival in service despite the low efficiency of engines of these cars and increase their consumption of fuel compared to modern cars Thereby increasing their harmful emissions. The researcher discussed the theoretical aspect of the research to the problem of research and the increase in the volume of environmental pollutants produced by the 374

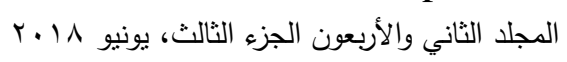




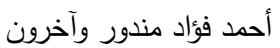

industrial and technical changes that prevailed throughout the world, including Egypt, and increase the size of contaminants for car exhausts. The research aims to activate the role of environmental taxes in the treatment of pollutants caused by car exhausts, And the construction of a proposed model and a mechanism for the enforcement of the environmental tax on cars in Egypt. The study adopted the basic premise: "The application of the environmental tax to pollutants caused by car exhausts has significant positive effects on the environmental level.

Keywords: Environmental taxation; environmental regulation; preexisting taxes; tax interactions; Government expenditure 